Check for updates

Cite this: RSC Adv., 2018, 8, 31440

Received 5th July 2018

Accepted 26th August 2018

DOI: $10.1039 / c 8 r a 05726 e$

rsc.li/rsc-advances

\section{Sodium dodecylsulfate-layered double hydroxide and its use in the adsorption of $17 \beta$-estradiol in wastewater}

\begin{abstract}
Yuan Kong, (D) $\uparrow^{\mathrm{a}}$ Yangrui Huang, $\uparrow^{\mathrm{b}}$ Chenrui Meng ${ }^{\mathrm{b}}$ and Zhi Zhang ${ }^{\star a}$
Modified $\mathrm{Mg}_{3} \mathrm{Al}$ layered double hydroxide (LDH) intercalated with dodecylsulfate anion composites, which were designated as SDS-LDH composites, were synthesized by coprecipitation. The samples were characterized using SEM, EDX, FT-IR, zeta potential analysis, and XRD. The results showed that the SDSLDH composites contain a thicker and larger porous interconnected network than inorganic LDH due to the enlarged inter-layer distance. The outstanding adsorption performance of SDS-LDH composites toward $17 \beta$-estradiol (E2) was investigated under different conditions, including solution $\mathrm{pH}$, adsorbent dosage, ion strength, reaction time, and temperature. When the solution $\mathrm{pH}$ was 7 and the adsorbent dosage was $2 \mathrm{~g} \mathrm{~L}^{-1}$, the removal rate of E2 reached the maximum at 94\%, whereas inorganic $\mathrm{LDH}$ displayed a poor $\mathrm{E} 2$ removal rate of $10 \%$. The presence of various ions $\left(\mathrm{Na}^{+}, \mathrm{SO}_{4}{ }^{2-}, \mathrm{Cl}^{-}\right.$, and $\left.\mathrm{H}_{2} \mathrm{PO}_{4}{ }^{-}\right)$in aqueous solution exerted no significant adverse effects on the adsorption process. The adsorption equilibrium was reached within $20 \mathrm{~min}$, and the adsorption fitted well with the pseudo-second-order model and the Freundlich isotherm. The thermodynamic test revealed that the adsorption process was spontaneous and endothermic. Phosphorus was selected as the index for evaluating the adsorption capacity of SDS-LDH composites for inorganic ions. The removal rates of total phosphorus and $\mathrm{PO}_{4}{ }^{3-}$ were $43.71 \%$ and $55.93 \%$ for SDS-LDH composites at $2 \mathrm{~g} \mathrm{~L}^{-1}$. The removal rate of $\mathrm{PO}_{4}{ }^{3-}$ reached up to $85 \%$ when the contact time was $120 \mathrm{~min}$ and the dosage was $3 \mathrm{~g} \mathrm{~L}^{-1}$ for SDS-LDH composites, which were approximately close to those of inorganic $\mathrm{LDH}$ of $30 \mathrm{~min}$ and $2 \mathrm{~g} \mathrm{~L}^{-1}$, respectively. This finding indicates that the removal capacity of SDS-LDH composites for $\mathrm{PO}_{4}{ }^{3-}$ decreased after the dodecylsulfate anions intercalated into the interlayer. The composites retained their high efficiency and stability after desorption and regeneration with alkali treatment. This study demonstrated that SDS-LDH composites are a promising adsorbent for the recovery and abatement of trace-level E2 in secondary effluents of wastewater treatment plants.
\end{abstract}

\section{Introduction}

The abundance of environmental estrogens, particularly endocrine-disrupting compounds, which are considered emerging persistent compounds, is potentially endangering the ecological health in environmental water and affecting the normal activity of the endocrine system in both wildlife and humans. ${ }^{1}$ Among these compounds, the natural hormone $17 \beta$ estradiol (E2) is a highly endocrine-disrupting agent. On the one hand, E2 is unlikely the most probable cause of endocrine disruption effects in fish and other animal species. ${ }^{2}$ On the

${ }^{a}$ Key Laboratory of the Three Gorges Reservoir Region's Eco-Environment, Ministry of Education, Chongqing University, Chongqing 400045, China. E-mail: zhangzhicqu@ cqu.edu.cn

${ }^{b}$ School of Environmental Studies, China University of Geosciences, Wuhan 430074, Hubei, China

$\uparrow$ These two authors contributed equally to this study and should be regarded as joint first authors. other hand, E2 is associated with endocrine and reproductive complications, including uterine fibroids, breast cancer in women, and testicular and prostate cancers in men., ${ }^{1,3,4}$ E2 has been detected in different types of water, including drinking water, natural water bodies, and wastewater treatment plant effluents and sludge throughout Europe, Asia, and the United States. ${ }^{5,21}$ The E2 levels in groundwater reportedly range from below $1 \mathrm{ng} \mathrm{\textrm {L } ^ { - 1 }}$ to $64 \mathrm{ng} \mathrm{\textrm {L } ^ { - 1 }}$, and $\mathrm{E} 2$ exhibits a high physiological activity even at very low concentrations. The removal rate of environmental estrogens, including E2, by municipal wastewater treatment plants ranges from $50 \%$ to $90 \% .^{6}$ In environmental water, the degradation of $\mathrm{E} 2$ and related compounds typically lasts for numerous hours to months or even several years. Various methods, such as photocatalytic degradation, zonation, activated sludge, and adsorption, have been established to remove environmental estrogens. For example, Silva C. P. et al. ${ }^{7}$ used simulated solar radiation to investigate the photodegradation of $17 \alpha$-ethinylestradiol (EE2) and E2 in the presence of fulvic acids. Coleman et $a l .{ }^{8}$ investigated the 
removal efficiency of $\mathrm{E} 2$ by adding powdered $\mathrm{TiO}_{2}$ into a photocatalytic degradation system. Irmak et al. ${ }^{9}$ explored the treatment efficiency of E2 in ozone $\left(\mathrm{O}_{3}\right)$ and $\mathrm{O}_{3}$ /ultraviolet (UV) systems. However, the treatment efficiency is restricted by external conditions, and the cost is always very high. In contrast to these methods, adsorption has become the most promising technique because of its easy synthesis, low cost, and high efficiency. For example, Fukuhara T. et al. ${ }^{10}$ investigated the adsorption performance of estrone and estradiol dissolved in ultra-pure water by using activated carbon, and they obtained remarkable results. Yoon Y. et al. ${ }^{11}$ investigated the adsorption performance of ${ }^{3} \mathrm{H}$-labeled E2 by using powdered activated carbon and obtained maximum final removal rates up to $90 \%$. Unfortunately, when traditional adsorbents are applied, competitive adsorption may adversely affect the adsorption process.

Layered double hydroxides (LDHs) consist of positively charged brucite-type layers of divalent and trivalent metallic hydroxide and exchangeable anions located in the interlamellar that are used to balance the positive charge, and LDHs are considered a typical anionic clay. ${ }^{11-13}$ The unusual physicochemical properties of LDHs are due to the unique lamellar structure and wide combination range of the components of both layers and interlayers. Given their specific properties, such as surface adsorption, surface complexation, ion exchange, and memory effect, LDH composites are regarded as promising materials for adsorbing pollutant. ${ }^{\mathbf{1 4}}$ Traditional LDHs synthesized by coprecipitation or ion exchange are hydrophilic, resulting in a low affinity for non-ionic organic compounds. ${ }^{1}$ However, the hydrophobic interaction between LDH composites and hydrophobic pollutants could be improved by replacing the interlamellar components with specific anions to enhance the affinity toward hydrophobic pollutants. ${ }^{15,16}$ These modified LDHs have a wide range of applications in the control of organic pollution fields. ${ }^{\mathbf{1 7 - 1 9}}$

In these experiments, we used coprecipitation to modify layered double hydroxides intercalated with dodecylsulfate anions, which were designated as SDS-LDH composites. ${ }^{19}$ The formed materials were systematically characterized by scanning electron microscopy (SEM), energy dispersive X-ray (EDX), Fourier transform infrared spectroscopy (FT-IR), Zeta potential and X-ray diffraction (XRD) to evaluate their adsorption efficiency and clarify the adsorption mechanism of E2. Then, adsorption experiments were conducted under different conditions, including solution $\mathrm{pH}$, adsorbent dosage, ion strength, contact time, and temperature. The adsorption kinetics, adsorption isotherm, and adsorption thermodynamics of E2 were analyzed to elucidate the adsorption mechanism. Cyclic adsorption experiments were performed to evaluate the practicability of the adsorbents and improve the process economics. Phosphorus were used to evaluate the change in adsorption capacity for inorganic matter after modification. Corresponding experiments involved the removal rates of TP (total phosphorus) and $\mathrm{PO}_{4}{ }^{3-}$ by SDS-LDH composites with $2 \mathrm{~g}$ $\mathrm{L}^{-1}$ and the comparison of removal efficiency of $\mathrm{PO}_{4}{ }^{3-}$ between SDS-LDH composites and inorganic LDH. In view of the effects of E2 on environmental systems, our findings are critical to understanding the key factors influencing natural photodegradation processes. The results of this study may aid in the management of this environmental stressor.

\section{Materials and methods}

\subsection{Materials}

The $17 \alpha$-estradiol and E2 used in this study were purchased from J\&K in powder form with a purity of 99\%. Their molecular structure and relevant physicochemical properties are summarized in Table $1 .^{20}$ The organic anion dodecylsulfate used in preparing the organo/LDH nanohybrid was purchased from Sinopharm Chemical Reagent Co., Ltd. with a $>99 \%$ purity. All other solvents and reagents (Sinopharm Chemical Reagent Co., Ltd.) were of analytical grade and used without further purification. The wastewater used in all experiments was the filtered secondary effluent of the Long Wang Zui Wastewater Treatment Plant.

\subsection{Preparation of SDS-LDH and inorganic LDH composites}

SDS-LDH composites were synthesized by coprecipitation under $\mathrm{N}_{2}$ atmosphere and $\mathrm{CO}_{2}$-free water. ${ }^{12} \mathrm{~A} 100 \mathrm{~mL}$ aqueous solution labeled as "solution A" contained $0.06 \mathrm{~mol}$ of $\mathrm{Mg}\left(\mathrm{NO}_{3}\right)_{2} \cdot 6 \mathrm{H}_{2} \mathrm{O}$ and $0.02 \mathrm{~mol}$ of $\mathrm{Al}\left(\mathrm{NO}_{3}\right)_{3} \cdot 9 \mathrm{H}_{2} \mathrm{O}(\mathrm{Mg} / \mathrm{Al}$ ratio = 3), and another $500 \mathrm{~mL}$ alkaline solution denoted as "solution B" contained $0.16 \mathrm{~mol}$ of $\mathrm{NaOH}$ and $0.05 \mathrm{~mol}$ of sodium dodecylsulfate. Solution A was added dropwise to solution B. Then, the mixture was homothermally treated at $80{ }^{\circ} \mathrm{C}$ for $24 \mathrm{~h}$ and aged. The suspension was centrifuged at a high speed and washed with $\mathrm{CO}_{2}$-free water for several times. Finally, the samples were freeze dried, and the SDS-LDH composites were obtained. The

Table 1 Molecular structure and physicochemical properties of $17 \alpha$-estradiol and E2

\begin{tabular}{|c|c|c|c|c|c|c|}
\hline Molecule & Chemical formula & Molecule structure & $\mathrm{MW}\left(\mathrm{g} \mathrm{moL}^{-1}\right)$ & Water solubility $\left(\mathrm{mg} \mathrm{L}^{-1}\right)$ & $\lg K_{\text {ow }}$ & $\mathrm{p} K_{\mathrm{a}}$ \\
\hline $17 \beta$-Estradiol & $\mathrm{C}_{18} \mathrm{H}_{24} \mathrm{O}_{2}$ & & 272.38 & 13 & 3.94 & 10.71 \\
\hline
\end{tabular}




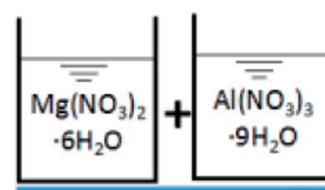

Homothermal, $25^{\circ} \mathrm{C}$ $\mathrm{N}_{2}, \mathrm{Mix}$

Homothermal, $25^{\circ} \mathrm{C}$ $\mathrm{N}_{2}$, Mix, $2 \mathrm{~h}$

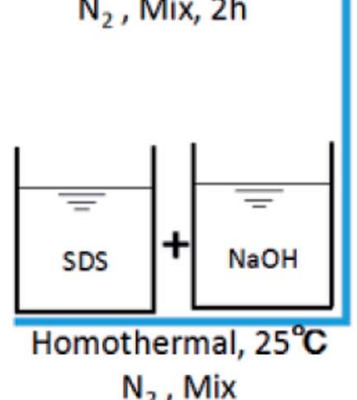

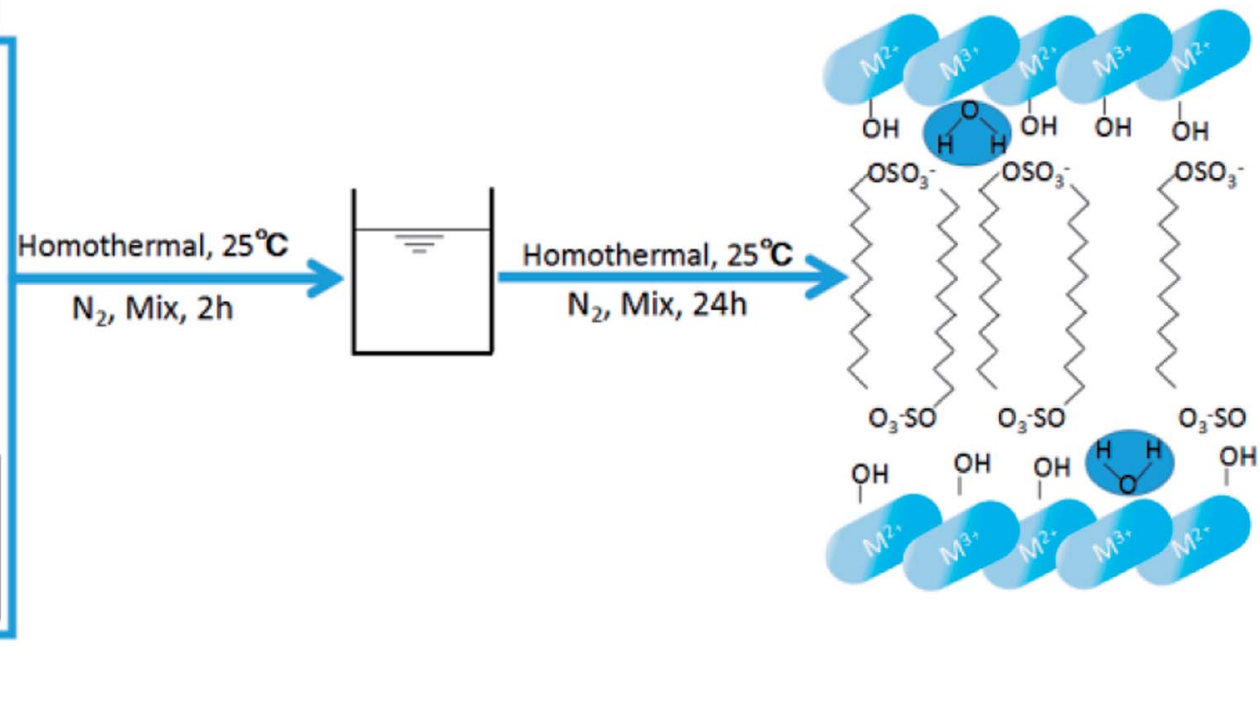

Scheme 1 Synthetic routes and schematic illustrations of SDS-LDH composites.

synthetic routes and schematic illustrations of the SDS-LDH composites are presented in Scheme 1.

For comparison, inorganic LDH was prepared by coprecipitation. ${ }^{12}$ A $100 \mathrm{~mL}$ aqueous solution labeled as "solution C" contained $0.075 \mathrm{~mol}$ of $\mathrm{Mg}\left(\mathrm{NO}_{3}\right)_{2} \cdot 6 \mathrm{H}_{2} \mathrm{O}$ and $0.025 \mathrm{~mol}$ of $\mathrm{Al}\left(\mathrm{NO}_{3}\right)_{3} \cdot 9 \mathrm{H}_{2} \mathrm{O}(\mathrm{Mg} / \mathrm{Al}$ ratio $=3)$, and another $500 \mathrm{~mL}$ alkaline solution designated as "solution D" contained $0.2 \mathrm{~mol}$ of $\mathrm{NaOH}$ and $0.0375 \mathrm{~mol}$ of $\mathrm{Na}_{2} \mathrm{CO}_{3}$. Solution $\mathrm{C}$ was added dropwise to solution D. Then, inorganic LDH was obtained through the same process as described.

\subsection{Characterization}

The SDS-LDH composites and inorganic LDH composites were characterized using different physicochemical techniques. SEM images were captured using a SU8010 (Hitachi Co., Japan) instrument at a voltage of $1 \mathrm{kV}$ and a resolution of up to $1.3 \mathrm{~nm}$. Elemental chemical analysis was conducted through atomic absorption spectrometry on an APOLLO XP (Ametek Co., USA) instrument. EDX spectroscopy revealed the main elementals analysis results, including the weight (\%) and atomic ratio of the SDS-LDH and inorganic LDH composites. FT-IR was performed using a Nicolet6700 (Bruker, USA) instrument. The XRD diagrams were collected at room temperature under air conditions by using a Bruker AXS D8-Focus X-ray diffractometer instrument with $\mathrm{Cu} \mathrm{K}_{\alpha}$ radiation $(\lambda=0.154050 \mathrm{~nm})$ and quartz as the external standard. The interlamellar pacing was calculated using the following equation:

$$
d=\frac{n \lambda}{2 \sin \theta},
$$

where $d(\mathrm{~nm})$ is the interlamellar spacing, $n(n=1)$ is the diffraction series, $\lambda(\lambda=0.154050 \mathrm{~nm})$ is the wavelength of the $\mathrm{X}$-ray, and $\theta$ represents the half of the diffraction angle.

\subsection{Analysis methods}

E2 was analyzed by high-performance liquid chromatography (HPLC). The chemicals were separated on a Waters PAH C-18 (S$5 \mu \mathrm{m}, 250 \mathrm{~mm} \times 4.6 \mathrm{~mm}$ column) with $60: 40$ acetonitrile/ water as the mobile phase. The equipment was run for $10 \mathrm{~min}$ at a flow rate of $0.8 \mathrm{~mL} \mathrm{~min}{ }^{-1}$. A $20 \mu \mathrm{L}$ injection volume of $\mathrm{E} 2$ was analyzed by HPLC with the use of a UV detector at $279 \mathrm{~nm}$ and a fluorescence detector operating simultaneously in series. The concentrations of $\mathrm{PO}_{4}{ }^{3-}$ and $\mathrm{TP}$ in the samples were measured by the ascorbic acid-molybdenum blue method and the potassium persulfate digestion-ascorbic acid-molybdenum blue method, respectively. For all extractions, after treatment, the sample was centrifuged and passed through a $0.45 \mu \mathrm{m}$ filter to separate the extract from the residue. ${ }^{12}$

The adsorption amounts $q_{\mathrm{t}}\left(\mathrm{mg} \mathrm{g}^{-1}\right)$ were calculated using the following equation:

$$
q_{t}=\frac{C_{0}-C_{t}}{m} V
$$

The removal rates were calculated using the following equation:

$$
\text { Removal rates }(\%)=\frac{C_{0}-C_{t}}{C_{0}} \times 100 \%,
$$

where $C_{0}\left(\mathrm{mg} \mathrm{L}^{-1}\right)$ is the initial concentration of $\mathrm{E} 2, \mathrm{TP}, \mathrm{PO}_{4}{ }^{3-}$, and organophosphorus; $C_{t}\left(\mathrm{mg} \mathrm{L}^{-1}\right)$ is the concentration of $\mathrm{E} 2$, $\mathrm{TP}, \mathrm{PO}_{4}{ }^{3-}$, and organophosphorus at time $t(\mathrm{~min}) ; V(\mathrm{~L})$ is volume of the solution; and $m(\mathrm{mg})$ is the weight of the adsorbent. 


\subsection{Adsorption experiments}

2.5.1 Preparation of the main solutions. The mother solution of $17 \alpha$-estradiol (1000 ppm), which was marked as "MA", was prepared by dissolving $1.00 \mathrm{~g}$ of white powdery $17 \alpha$-estradiol in $1000 \mathrm{~mL}$ of methanol and was used as an internal standard. The mother solution of E2 (1000 ppm), which was marked as "MB", was prepared by dissolving $1.00 \mathrm{~g}$ of white powdery $17 \beta$-estradiol in $1000 \mathrm{~mL}$ of methanol. The stock solutions were covered with aluminum foil to prevent any photodegradation at $4{ }^{\circ} \mathrm{C}$. The mother solution of $\mathrm{KH}_{2} \mathrm{PO}_{4}(1000$ ppm) was labeled as "MP" and the concentration of MP was calculated by the amount of $\mathrm{P}$ being $1000 \mathrm{ppm}$, so "MP" was prepared by weighing $4.394 \mathrm{~g}$ of $\mathrm{KH}_{2} \mathrm{PO}_{4}$, which was dissolved in ultra-pure water and transferred to a volumetric flask $(1000 \mathrm{~mL})$.

2.5.2 Adsorption reaction of $\mathbf{E} 2$ and phosphorus. The adsorption experiments toward E2 was investigated under different conditions, including solution $\mathrm{pH}$, adsorbent dosage, ion strength, contact time, and temperature. The aqueous solution used in this experiment was the secondary effluent of a wastewater treatment plant with a certain amount of MB. Prior to the adsorption experiments, both the SDS-LDH composites and inorganic LDH composites were dried in a freeze dryer. To reach the adsorption equilibrium, the mixtures was stirred with a magnetic stirrer at $200 \mathrm{rpm}$ for $45 \mathrm{~min}$.

The effect of $\mathrm{pH}$ was investigated by adjusting the initial $\mathrm{pH}$ of the solutions with $0.1 \mathrm{~mol} \mathrm{~L}^{-1} \mathrm{HCl}$ and $0.1 \mathrm{~mol} \mathrm{~L}^{-1} \mathrm{NaOH}$, and the $\mathrm{pH}$ range was from 3 to 10 . Approximately $0.06 \mathrm{~mL}$ of $\mathrm{MB}$ was added to $200 \mathrm{~mL}$ of filtered sewage. The solution volume, dosage, $C_{0}$, and temperature were $200 \mathrm{~mL}, 2 \mathrm{~g} \mathrm{~L}^{-1}$, $0.319 \mathrm{mg} \mathrm{L}^{-1}$, and $298 \mathrm{~K}$, respectively. The effect of adsorbent dosage was assessed by adding $0.06 \mathrm{~mL}$ of $\mathrm{MB}$ to $200 \mathrm{~mL}$ of filtered sewage with different SDS-LDH composites dosages ranging from $0.2 \mathrm{~g} \mathrm{~L}^{-1}$ to $3.5 \mathrm{~g} \mathrm{~L}^{-1}$. The solution volume, $\mathrm{pH}, C_{0}$, equilibrium time, and temperature were $200 \mathrm{~mL}, 7$, $0.319 \mathrm{mg} \mathrm{L}^{-1}, 45 \mathrm{~min}$, and $298 \mathrm{~K}$, respectively. Then, the adsorption isotherm experiments were repeated at 308 and 318 $\mathrm{K}$. The effect of ion strength was examined by gradually increasing the $\mathrm{Na}_{2} \mathrm{SO}_{4}, \mathrm{NaCl}$, and $\mathrm{NaH}_{2} \mathrm{PO}_{4}$ concentrations from $2 \mathrm{~g} \mathrm{~L}^{-1}$ to $10 \mathrm{~g} \mathrm{~L}^{-1}$. Approximately $0.06 \mathrm{~mL}$ of $\mathrm{MB}$ was added to $200 \mathrm{~mL}$ of filtered sewage. The solution volume, $\mathrm{pH}$, dosage, $C_{0}$, equilibrium time, and temperature were $200 \mathrm{~mL}, 7$, $2 \mathrm{~g} \mathrm{~L}^{-1}, 0.319 \mathrm{mg} \mathrm{L}^{-1}, 45 \mathrm{~min}$, and $298 \mathrm{~K}$, respectively. The effect of temperature was analyzed at $298 \mathrm{~K}$ by adding $2 \mathrm{~g} \mathrm{~L}^{-1}$ of adsorbents into aqueous solution $(200 \mathrm{~mL}, \mathrm{pH}=7)$ at different initial concentrations $\left(0.301,0.275\right.$, and $\left.0.260 \mathrm{mg} \mathrm{L}^{-1}\right)$ for $45 \mathrm{~min}$. Then, the adsorption isotherm experiments were repeated at 308 and $318 \mathrm{~K}$.

The adsorption experiments toward phosphorus was to evaluating the adsorption capacity of SDS-LDH composites for inorganic ions. Corresponding experiments involved the removal rates of TP and $\mathrm{PO}_{4}{ }^{3-}$ by SDS-LDH composites with $2 \mathrm{~g}$ $\mathrm{L}^{-1}$ and the comparison of removal efficiency of $\mathrm{PO}_{4}{ }^{3-}$ between SDS-LDH composites and inorganic LDH. The aqueous solution of these experiment was the filtered secondary effluent of a wastewater treatment plant added with a certain amount of MP. Prior to the adsorption experiments, both the SDS-LDH composites and inorganic $\mathrm{LDH}$ composites were dried in a freeze dryer. Based on the pre-experiment results, the mixtures were stirred with a magnetic stirrer at $200 \mathrm{rpm}$ for $3 \mathrm{~h}$ to reach the adsorption equilibrium.

To examine the removal rates of $\mathrm{TP}, \mathrm{PO}_{4}{ }^{3-}$ by SDS-LDH composites, we added $0.40 \mathrm{~mL}$ of $\mathrm{MP}$ to $200 \mathrm{~mL}$ of filtered sewage. The solution volume, $\mathrm{pH}$, dosage, equilibrium time, temperature, and $\mathrm{C}_{0}$ of TP and $\mathrm{PO}_{4}{ }^{3-}$ were $200 \mathrm{~mL}, 7,2.0 \mathrm{~g} \mathrm{~L}^{-1}$, $3 \mathrm{~h}, 298 \mathrm{~K}, 2.952$, and $2.379 \mathrm{mg} \mathrm{L}^{-1}$, respectively. The samples were double extracted at different times in which one sample was directly measured without digestion. The measurement of dissolved phosphorus was consistent with the aforementioned method. To evaluating the adsorption capacity of SDS-LDH composites for inorganic ions, we compared the adsorption efficiency of $\mathrm{PO}_{4}{ }^{3-}$ by SDS-LDH composites $\left(2.0-3.0 \mathrm{~g} \mathrm{~L}^{-1}\right)$ and inorganic $\mathrm{LDH}\left(2.0 \mathrm{~g} \mathrm{~L}^{-1}\right)$, and the solution volume, $\mathrm{pH}, C_{0}$, and temperature were $200 \mathrm{~mL}, 7,2.378 \mathrm{mg} \mathrm{L}^{-1}$, and $298 \mathrm{~K}$, respectively.

\subsection{Adsorption kinetics}

To study the adsorption kinetics of SDS-LDH composites and inorganic $\mathrm{LDH}$ composites for $\mathrm{E} 2,0.15 \mathrm{~mL}$ of $\mathrm{MB}$ was added to $500 \mathrm{~mL}$ filtered sewage and performed the experiments under different conditions. The solution volume, $\mathrm{pH}$, dosage, $C_{0}$, equilibrium time, and temperature were $200 \mathrm{~mL}, 7,2 \mathrm{~g} \mathrm{~L}^{-1}$, $0.319 \mathrm{mg} \mathrm{L}^{-1}, 45 \mathrm{~min}$, and $298 \mathrm{~K}$, respectively. The samples were extracted at different times and analyzed.

The nonlinear forms of the pseudo-first-order and pseudosecond-order kinetic models are expressed as the following equations:

$$
\begin{gathered}
q_{t}=q_{\mathrm{e}}\left(1-\mathrm{e}^{-k_{1} t}\right), \\
q_{t}=\frac{k_{2} q_{\mathrm{e}}^{2} t}{1+k_{2} q_{\mathrm{e}} t},
\end{gathered}
$$

where $q_{\mathrm{e}}\left(\mathrm{mg} \mathrm{g}^{-1}\right)$ is the equilibrium adsorption amounts; $q_{t}$ $\left(\mathrm{mg} \mathrm{g}^{-1}\right)$ is the adsorption amount varying with $t ; t(\mathrm{~s})$ is the contact time; and $k_{1}\left(\mathrm{~s}^{-1}\right)$ and $k_{2}\left(\mathrm{~g} \mathrm{mg}^{-1} \mathrm{~s}^{-1}\right)$ are the rate constants of the pseudo-first-order and pseudo-second-order models, respectively.

The linear forms of the Langmuir and Freundlich models are given as follows:

$$
\begin{gathered}
\frac{C_{\mathrm{e}}}{q_{\mathrm{e}}}=\frac{C_{\mathrm{e}}}{Q_{\mathrm{m}}}+\frac{1}{K_{\mathrm{L}} Q_{\mathrm{m}}}, \\
\ln q_{\mathrm{e}}=\frac{1}{n} \ln C_{\mathrm{e}}+\ln K_{\mathrm{f}},
\end{gathered}
$$

where $q_{\mathrm{e}}\left(\mathrm{mg} \mathrm{g}^{-1}\right)$ is the equilibrium adsorption amount; $C_{\mathrm{e}}(\mathrm{mg}$ $\left.\mathrm{L}^{-1}\right)$ is the equilibrium adsorption concentration; $Q_{\mathrm{m}}\left(\mathrm{mg} \mathrm{g}^{-1}\right)$ is the maximum adsorption amount corresponding to the complete monolayer converge; $K_{\mathrm{L}}\left(\mathrm{L} \mathrm{mg}^{-1}\right)$ is the Langmuir constant related to the adsorption energy and the adsorption capability; and $K_{\mathrm{f}}\left(\mathrm{mg}^{1-1 / n} \mathrm{~L}^{1 / n} \mathrm{~g}^{-1}\right)$ and $n$ are the Freundlich constants representing the adsorption capacity and the adsorption intensity, respectively. Fig. 12 and 13 show the adsorption isotherm curves of E2 under different temperatures 


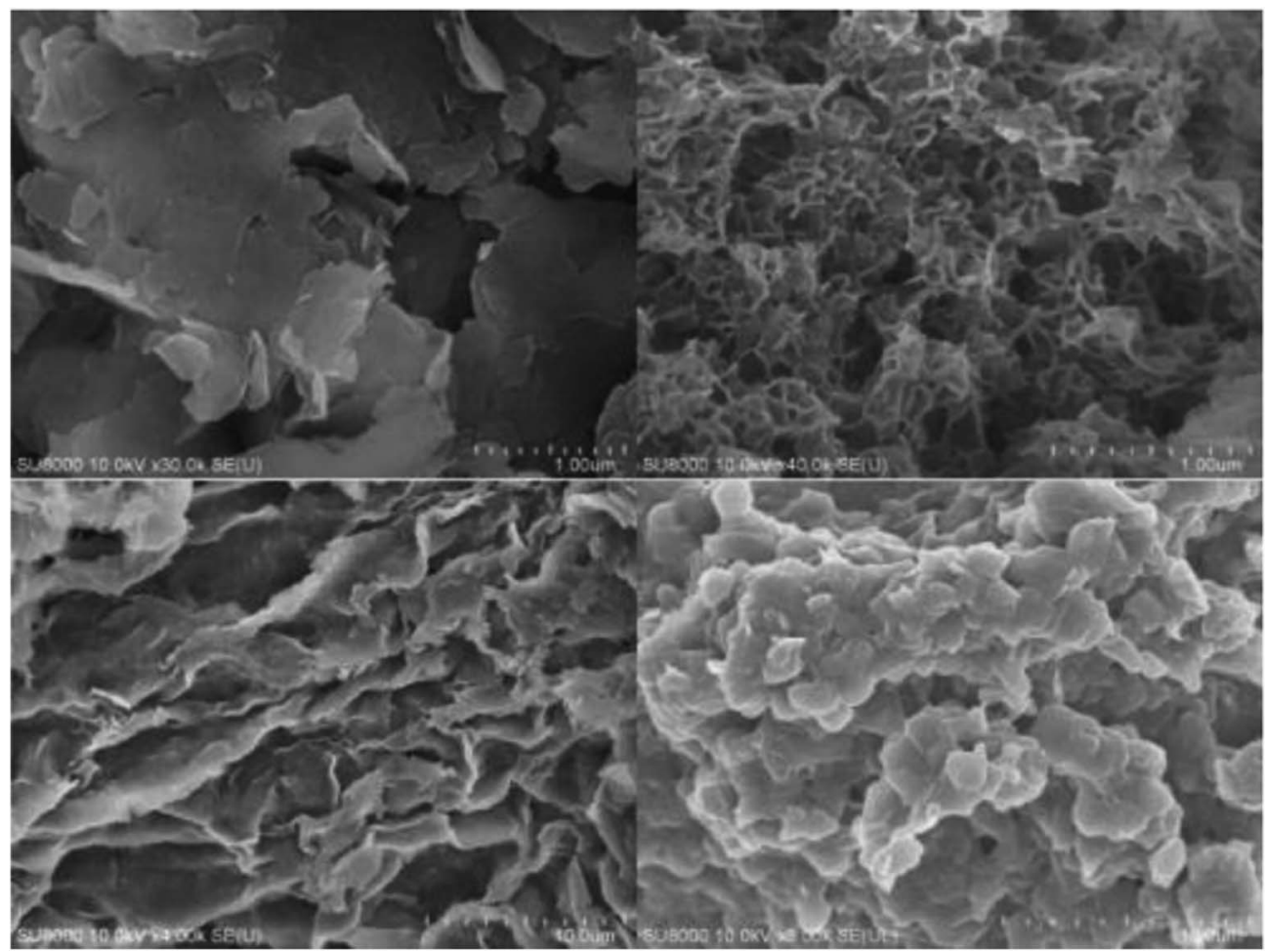

Fig. 1 SEM of inorganic LDH composite (left) and SDS-LDH composites (right).

and the corresponding linear fitting of the Langmuir and Freundlich (inset) models.

The apparent equilibrium constant $\left(K_{0}\right)$ can be expressed as follows:

$$
K_{0}=\frac{C_{\mathrm{ad}, \mathrm{e}}}{C_{\mathrm{e}}},
$$

where $C_{\mathrm{ad}, \mathrm{e}}(\mathrm{mg})$ is the equilibrium amount of $\mathrm{E} 2$ adsorbed on the adsorbent per liter of the solution, and $C_{\mathrm{e}}\left(\mathrm{mg} \mathrm{L}^{-1}\right)$ is the equilibrium concentration. $K_{0}$ can be obtained in the lowest experimental concentration of $\mathrm{E} 2$ and used to determine $\Delta G$, $\Delta H$, and $\Delta S$ by using the following equations:

$$
\begin{gathered}
\Delta G=-R T \ln K_{0}, \\
\Delta G=\Delta H-T \Delta S,
\end{gathered}
$$

where $\Delta G\left(\mathrm{~kJ} \mathrm{~mol}^{-1}\right)$ is the Gibbs free energy change, $\Delta H(\mathrm{~kJ}$ $\left.\mathrm{mol}^{-1}\right)$ is the enthalpy change, and $\Delta S\left(\mathrm{~J} \mathrm{~mol}^{-1} \mathrm{~K}^{-1}\right)$ is the entropy change.

\subsection{Cyclic adsorption experiments}

The desorption principle was adopted to explore the regeneration performance of SDS-LDH. The cycle adsorption experiments were divided into four groups. The $\mathrm{NaOH}$ concentrations used to wash the materials in each group were $2 \%, 5 \%, 8 \%$, and $10 \%$, and the adsorption-regeneration cycles were repeated five times for each $\mathrm{NaOH}$ concentration. For each adsorption test, the adsorbent dosage was $2 \mathrm{~g} \mathrm{~L}^{-1}$, the external E2 dosage was $0.3 \mathrm{ppm}$, and the initial $\mathrm{pH}$ was 7 . After being stirred in a $25^{\circ} \mathrm{C}$ water bath and reacted for $30 \mathrm{~min}$, the water sample was collected for further testing.

\section{Results and discussion}

\subsection{Characterization of the SDS-LDH and inorganic LDH composites}

The means of the SEM measurements were used to observe the microstructural surface of the materials, and the results are shown in Fig. 1. As shown, both SDS-LDH composites (right) and inorganic LDH composites (left) consisted of nanosheets, which is typical for layered double hydroxides. In contrast to the inorganic LDH composites, SDS-LDH composites contained a porous interconnected network that is thicker than that of inorganic LDH composites due to the enlarged inter-layer distance. The SDS-LDH composites displayed a typical spreading lamellar structure, and its layers were thin and diffused irregularly.

Table 2 provides the main elementals analysis results, including weight (\%) and the atomic ratios of SDS-LDH and inorganic LDH. As shown in Table 2, elemental analysis revealed no detectable amounts of $\mathrm{N}$ after dodecylsulfate was intercalated into the interlayer, indicating the lack of $\mathrm{NO}_{3}{ }^{-}$in the interlayer. Both the weight (\%) and atomic ratio of $\mathrm{C}$ and $\mathrm{S}$ were markedly increased, suggesting that dodecylsulfate replaced $\mathrm{CO}_{3}{ }^{2-}$ and $\mathrm{NO}_{3}{ }^{-}$into the interlayer. The molar ratio of $\mathrm{S} / \mathrm{AI}$ was 1.40 , which was higher than the required amount (S/AI $=1$ ) to replace the inorganic anions in the interlayer. Other researchers have also reported this phenomenon. You et al. ${ }^{22}$ 
Table 2 SEM-EDX parameters of SDS-LDH composites

\begin{tabular}{|c|c|c|c|}
\hline & & SDS-LDH & Inorganic LDH \\
\hline \multirow{4}{*}{ Weight (\%) } & $\mathrm{Mg}$ & 10.40 & 21.67 \\
\hline & $\mathrm{Al}$ & 3.92 & 7.9 \\
\hline & $\mathrm{S}$ & 6.51 & - \\
\hline & $\mathrm{N}$ & 0.051 & 1.37 \\
\hline \multirow[t]{2}{*}{ Atomic ratio } & $\mathrm{S} / \mathrm{AI}$ & 1.40 & - \\
\hline & N/AI & 0.025 & 0.33 \\
\hline Proposed formulae & & {$\left[\mathrm{Mg}_{3} \mathrm{Al}(\mathrm{OH})_{7.975}(\mathrm{NO} 3)_{0.025}(\mathrm{DDS}) \cdot 4 \mathrm{H}_{2} \mathrm{O}\right](\mathrm{NaDDS})_{0.4}$} & $\mathrm{Mg}_{2.5} \mathrm{Al}(\mathrm{OH})_{7}\left(\mathrm{CO}_{3}\right)_{0.5} \cdot 2.8 \mathrm{H}_{2} \mathrm{O}$ \\
\hline
\end{tabular}

found that the excessive dodecylsulfate intercalated into the interlayer could be due to non-polar interactions with the hydrophobic alkyl groups of the intercalated dodecylsulfate. Rojas et al. ${ }^{23}$ confirmed that dodecylsulfate has a high affinity for the LDH surface in a previous study, which mainly focused on the effect on the surface charge characteristic of LDH after dodecylsulfate was intercalated.

The XRD patterns of the SDS-LDH composites and inorganic LDH composites samples are displayed in Fig. 2, and the XRD parameters are listed in Table 3. Three diffraction peaks $\left(d_{003}\right.$, $d_{006}$, and $d_{009}$ ) typical for SDS-LDH composites appeared in the low diffraction region, and they moved forward obviously compared with the same peaks typical for inorganic LDH. The

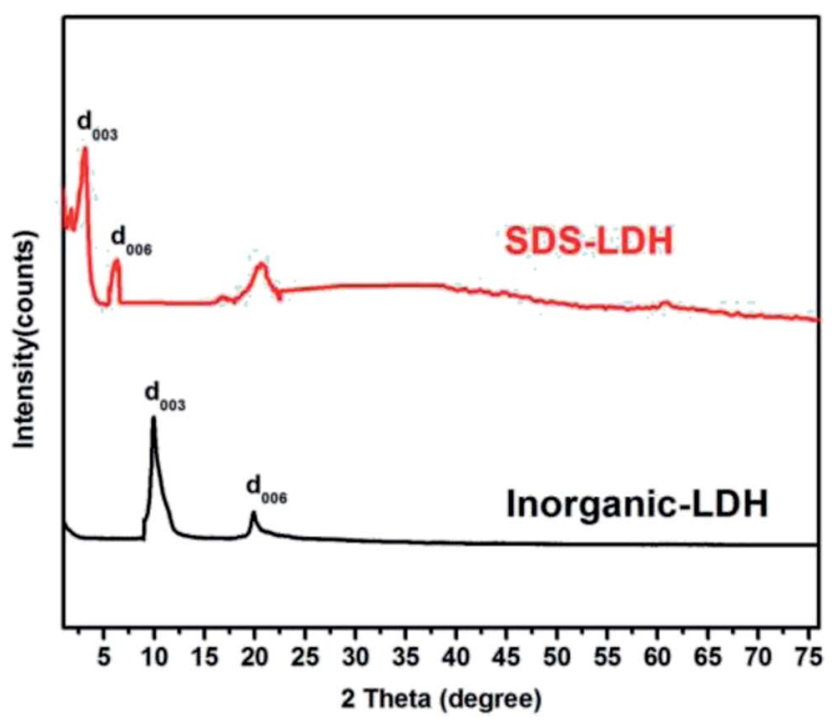

Fig. 2 XRD spectra of SDS-LDH and inorganic LDH composites.

Table 3 XRD parameters of SDS-LDH composites

\begin{tabular}{llllllll}
\hline Samples & $\begin{array}{l}2 \theta_{003} \\
\left({ }^{\circ}\right)\end{array}$ & $\begin{array}{l}d_{003} \\
(\mathrm{~nm})\end{array}$ & \multicolumn{1}{c}{$\begin{array}{l}2 \theta_{006} \\
\left.{ }^{\circ}\right)\end{array}$} & $\begin{array}{l}d_{006} \\
(\mathrm{~nm})\end{array}$ & $\begin{array}{l}d_{\text {layer }} \\
(\mathrm{nm})\end{array}$ & $\begin{array}{l}d \\
(\mathrm{~nm})\end{array}$ & $\begin{array}{l}d_{\mathrm{SDS}} \\
(\mathrm{nm})\end{array}$ \\
\hline SDS-DLH & 3.18 & 2.78 & 6.29 & 1.40 & 0.49 & 2.29 & 2.08 \\
Inorganic & 9.98 & 0.89 & 19.89 & 0.45 & 0.49 & 0.40 & 2.08 \\
LDH & & & & & & &
\end{tabular}

basal spacing $(d)$ of the layered materials could be calculated from the basal reflection by using eqn (1). The observed basal spacings, $d_{003}$, for SDS-LDH composites and inorganic LDH composites were 3.18 and $9.18 \AA$, and their corresponding layer spacings were 2.78 and $0.89 \mathrm{~nm}$, indicating that the SDS-LDH composites inter-layer spacing was greater than that of inorganic LDH composites. ${ }^{24}$ The intercalated SDS-LDH composites changed the positions of the (003), (006), (012), and (110) diffraction reflections presumably because in SDS-LDH composites, the chemical composition and therefore the morphology of the LDH were changed. ${ }^{25-27}$ Given that the length of dodecylsulfate was $2.08 \mathrm{~nm}$, it intercalated successfully into the interlayer and arranged the single layer in layers. Scheme 2 shown the structures of inorganic LDH composites (left) and SDS-LDH composites (right).

FT-IR analysis was performed to verify whether dodecylsulfate successfully intercalated into the interlayer. As shown in Fig. 3, the infrared spectra of SDS-LDH composites and inorganic LDH composites showed the characteristic absorption bands according to the hydrotalcite structure and composition. On the one hand, both of them showed a broad band centered at $3503 \mathrm{~cm}^{-1}$ due to the stretching mode of $\mathrm{OH}$, the stretching vibration bands of the hydration water molecules, and the $\mathrm{OH}^{-}$groups of the brucite-like layers. The peaks at $1393 \mathrm{~cm}^{-1}$ could be attributed to the vibration of $\mathrm{NO}_{3}{ }^{-}$. The peak intensity of SDS-LDH at this point sharply decreased compared with that of inorganic LDH. On the other hand, five peaks that belonged only to composites appeared in the spectra. The presence of dodecylsulfate in SDS-LDH composites was confirmed by the double in the $2850-2920 \mathrm{~cm}^{-1}$ region due to the $\mathrm{CH}$ stretching vibration bands $\left(2920\right.$ and $\left.2850 \mathrm{~cm}^{-1}\right)$ and the $\mathrm{C}-\mathrm{H}$ bending vibration band at $1460 \mathrm{~cm}^{-1}$. Bands due to the antisymmetric $\left(1224 \mathrm{~cm}^{-1}\right)$ and symmetric $\left(1060 \mathrm{~cm}^{-1}\right)$ sulfate $\mathrm{S}=\mathrm{O}$ stretching vibrations were also observed..$^{12,28}$ The correlated data are included in Table 4 . The results indicated that dodecylsulfate replaced $\mathrm{CO}_{3}{ }^{2-}$ and $\mathrm{NO}_{3}{ }^{-}$into the interlayer.

\subsection{Adsorption performance of $\mathrm{E} 2$ under different conditions}

3.2.1 Effect of $\mathbf{p H}$ on the adsorption of E2. The $\mathrm{pH}$ can influence the surface charge of the adsorbent material and the dissociation properties of organic contaminants. ${ }^{29}$ As shown in 


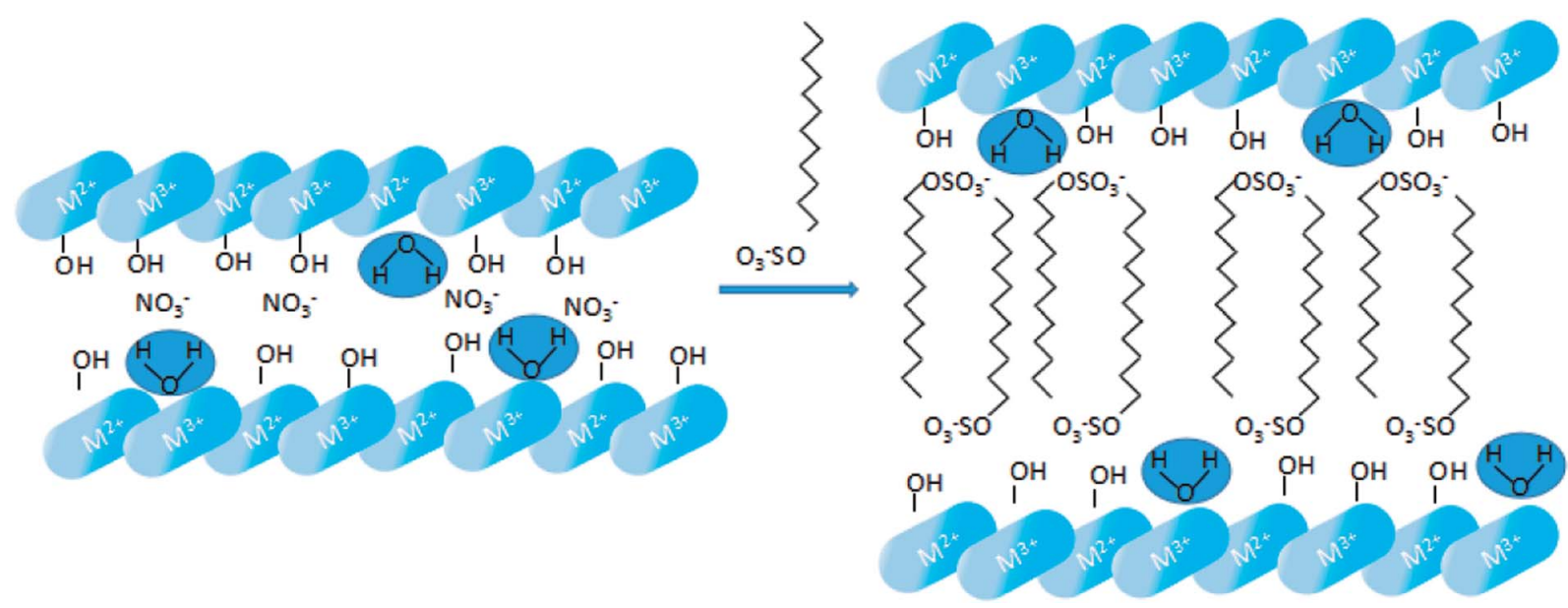

Scheme 2 Structures of inorganic LDH composites (left) and SDS-LDH (right).

Fig. 4 , the $q_{\mathrm{e}}$ of SDS-LDH remained relatively constant in the $\mathrm{pH}$ range of 3.0-9.0 and then rapidly decreased when the initial $\mathrm{pH}$ values exceeded 9.0. The zeta potential of SDS-LDH was zero when the $\mathrm{pH}=5.6$, indicating that the process of adsorption of E2 might be pH-independent and the SDS-LDH maintained a relatively high performance in both acidic and weakly basic solution. These inconsistent phenomenon between isoelectric point and $q_{\mathrm{e}}$ can be explained by hydrophobic interaction,

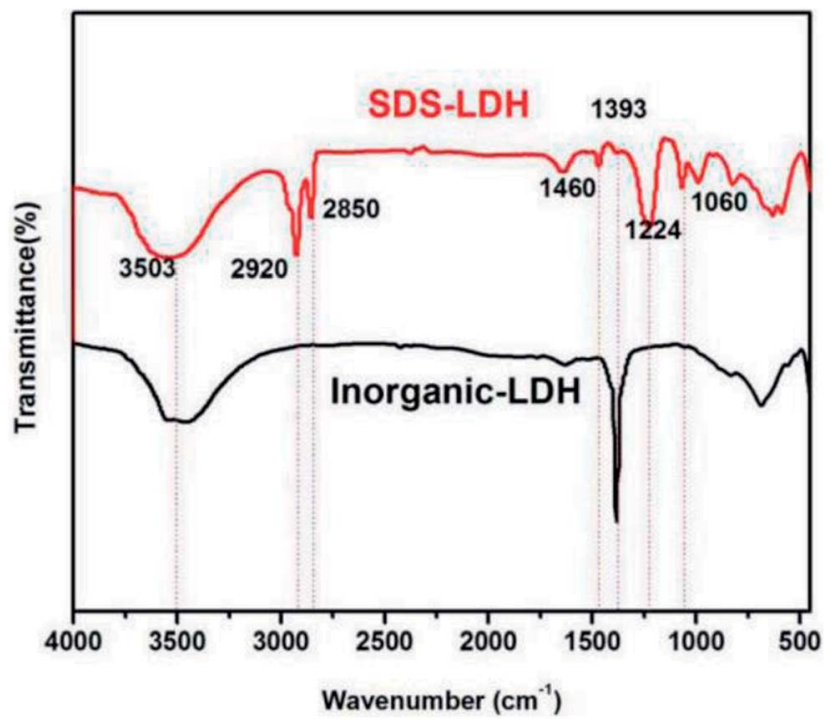

Fig. 3 FT-IR spectra of SDS-LDH and inorganic LDH composites.

Table 4 FT-IR parameters of SDS-LDH composites

\begin{tabular}{ll}
\hline Wavenumber $\left(\mathrm{cm}^{-1}\right)$ & Functional group \\
\hline 1224,1060 & $\mathrm{~S}=\mathrm{O}$ \\
1393 & $\mathrm{NO}_{3}{ }^{-}$ \\
1460 & $\mathrm{C}-\mathrm{H}$ \\
2850,2920 & $-\mathrm{CH}_{3} \&-\mathrm{CH}_{2}$ \\
3503 & $\mathrm{HO}^{-} \mathrm{OH}_{2} \& \mathrm{H}_{2} \mathrm{O} \cdots \mathrm{OH}_{2}$
\end{tabular}

hydrogen bond and dissociation properties of E2. When the initial $\mathrm{pH}$ of aqueous solution was less than 9.0, the dissociation of $\mathrm{E} 2\left(\mathrm{p} K_{\mathrm{a}}=10.71\right)$ was partially restrained, causing $\mathrm{E} 2$ to exist mostly in molecular form, ${ }^{30}$ therefore, even though the electrical charge of the SDS-LDH gradually changed from positive to negative ${ }^{31}$ (when $\mathrm{pH}$ exceeded 5.6), the electrostatic repulsion would not be the major force. Under this condition, the interaction between hydroxyl (from E2) and sulfonic group (from intercalated dodecylsulfate anions), or hydroxyl (boned to layer), can formed hydrogen bond and became one of the major force during the adsorption process. Another important force that existed during the adsorption process was hydrophobic interaction, the hydrophobic phase in the interlayer region was expected to have the ability to solubilize hydrophobic organic E2 compounds (the hydrophobic properties of SDS-LDH were going to be explained in Chapter 3.4.4.1). When the initial $\mathrm{pH}$ exceeded 9.0, the increased hydroxyl ion in aqueous promoted the dissociation of E2, and the main form was $\mathrm{E} 2$ anions. Thus the electrostatic repulsion between SDS-LDH and E2 anions

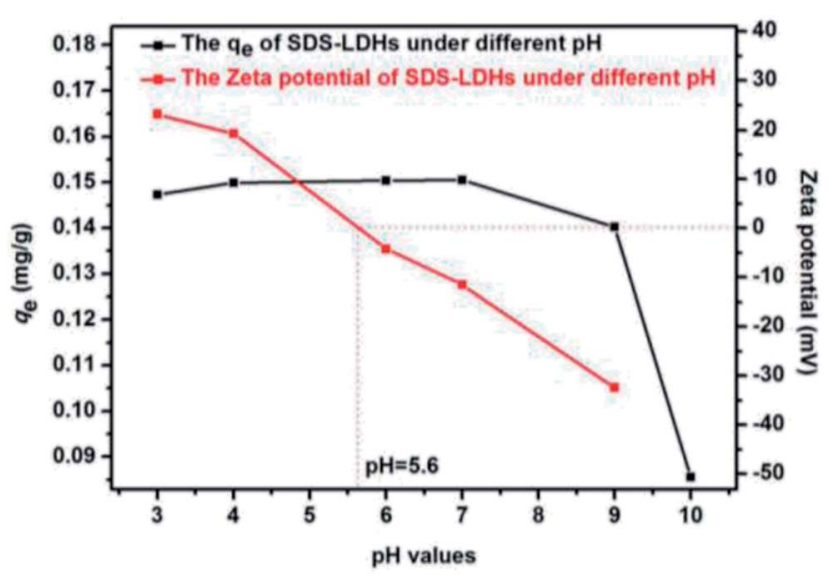

Fig. 4 Effect of solution $\mathrm{pH}$ for the adsorption of $17 \beta$-estradiol onto SDS-LDH composites and zeta potential of SDS-LDH composites (dosages $=2 \mathrm{~g} \mathrm{~L}^{-1}$, solutions $=0.319 \mathrm{mg} \mathrm{L}^{-1}, \mathrm{~V}=200 \mathrm{~mL}$, time $=$ $45 \mathrm{~min}$, temperature $=298 \mathrm{~K}$ ). 


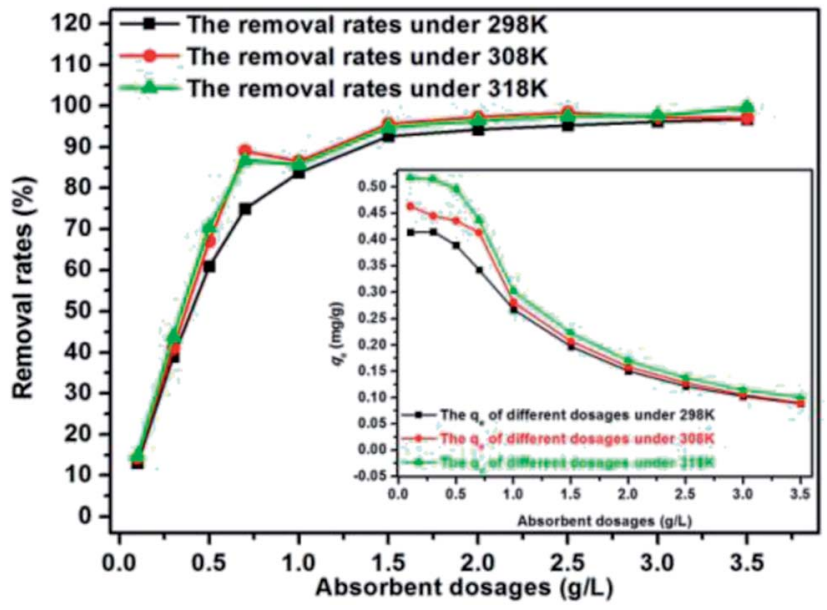

Fig. 5 Effect of adsorbent dosage for the adsorption of $17 \beta$-estradiol on removal rate and equilibrium adsorption amount $q_{\mathrm{e}}$ (inset) (solutions $=0.320 \mathrm{mg} \mathrm{L}^{-1}, \mathrm{~V}=200 \mathrm{~mL}, \mathrm{pH}=7$, time $=45 \mathrm{~min}$, temperature $=298 \mathrm{~K})$.

became the major force and $q_{\mathrm{e}}$ sharply decreased. Therefore, $\mathrm{pH}$ 7 was considered the optimal $\mathrm{pH}$ condition and used in subsequent experiments.

3.2.2 Effect of adsorbent dosage on the adsorption process of E2. The experiments about the effect of adsorbent dosage can determine the appropriate dosage of adsorbent, and the results can be used to explore the adsorption isotherms. The results under different temperature were presented in Fig. 5. It shown that the variation tendency in all three kind of experimental temperature ( $298 \mathrm{~K}, 308 \mathrm{~K}, 318 \mathrm{~K})$ are similar. One the one hand, the removal rate of $\mathrm{E} 2$ increased monotonously as the adsorbent dosage increased before reaching a maximum removal (dosage less than $2 \mathrm{~g} \mathrm{~L}^{-1}$ ), and then the removal rate changed slightly, indicating that the adsorption process reached equilibrium. This could be explained by the increased adsorption site with more SDS-LDH used. On the other hand, the $q_{\mathrm{e}}$ of SDS-LDH was gradually decreased with more SDS-LDH used. Therefore, $2 \mathrm{~g}$ $\mathrm{L}^{-1}$ was considered the optimal dosage and used in subsequent experiments.

3.2.3 Effect of ions on the adsorption of E2. Given that many ions existed in wastewater and that these ions participated in the adsorption process between absorbents and pollutants and consequently affected the functional groups on the adsorbent surface, ion strength was considered a significant factor in aqueous solution. As shown in Fig. 6, no obvious change occurred when the concentrations of $\mathrm{Na}_{2} \mathrm{SO}_{4}, \mathrm{NaCl}$, and $\mathrm{NaH}_{2} \mathrm{PO}_{4}$ were gradually increased. Thus, the ions did not compete with the E2 molecules adsorbed onto the absorbents. This finding, together with the previous experiment on the effect of $\mathrm{pH}$ on the adsorption process, revealed that the adsorption of $\mathrm{E} 2$ onto adsorbents exhibited $\mathrm{pH}$ dependence and ion independence.

3.2.4 Effect of reaction time on the adsorption of E2. The effect of contact time is presented in Fig. 7. The removal rate of E2 by SDS-LDH composites reached $94 \%$, whereas that by inorganic LDH composites was only $10 \%$. The adsorption

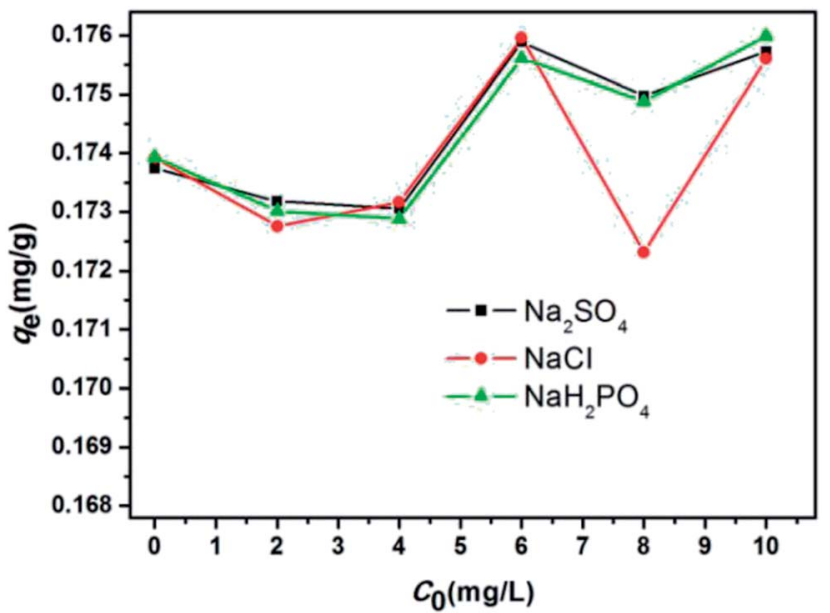

Fig. 6 Effect of ion strength for the adsorption of $17 \beta$-estradiol onto SDS-LDH composites (dosages $=2 \mathrm{~g} \mathrm{~L}^{-1}$, solutions $=0.379 \mathrm{mg} \mathrm{L}^{-1}, \mathrm{~V}$ $=200 \mathrm{~mL}, \mathrm{pH}=7$, reaction time $=45 \mathrm{~min}, T=298 \mathrm{~K}$ ).

process of SDS-LDH composites was rapid in the initial $3 \mathrm{~min}$ and then gradually slowed down compared with that of inorganic LDH. The adsorption equilibrium was reached within $20 \mathrm{~min}$. This phenomenon can be explained by the adsorption and desorption equilibrium. Numerous sorption sites initially appeared on the adsorbent surface. Thus, the adsorption rate was fast. Given that the adsorption sites on the surface were increasingly occupied by $\mathrm{E} 2$ during the adsorption process, the adsorption rate gradually decreased, and the desorption rate gradually increased. Then, the E2 molecules diffused into the interlayer of the adsorbents and were adsorbed through hydrogen bonding interactions with the sulfonic group belonging to the intercalated dodecylsulfate anions or hydroxyl of bound water and metal hydroxide. The E2 molecules were also adsorbed through hydrophobic interactions with the hydrophobic alkyl groups of intercalated dodecylsulfate, this process required a relatively long time. Finally, SDS-LDH composites was saturated when the desorption rate was equal

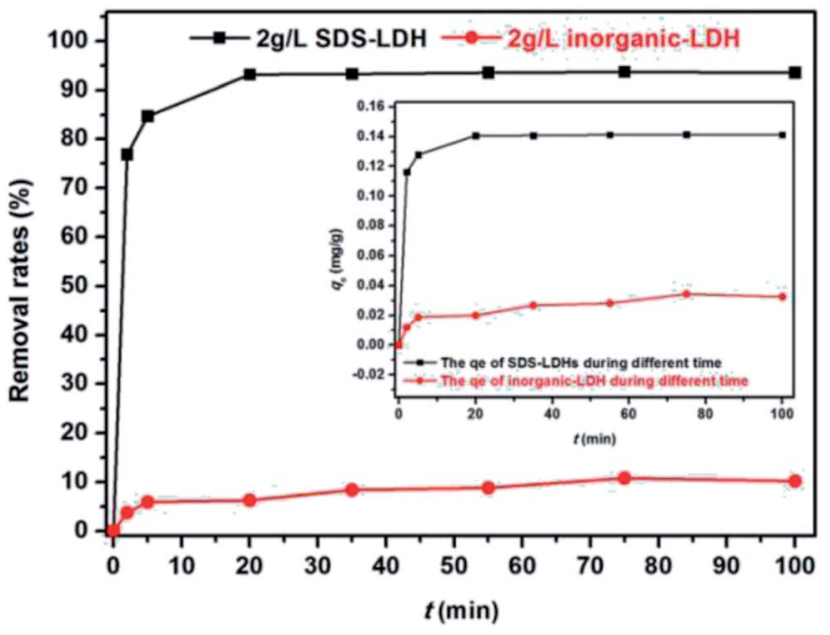

Fig. 7 Effect of contact time for the adsorption of $17 \beta$-estradiol on removal rates and the adsorption amount $q_{t}$ (inset) (dosages $=2 \mathrm{~g} \mathrm{~L}^{-1}$, solutions $=0.302 \mathrm{mg} \mathrm{L}^{-1}, V=500 \mathrm{~mL}, \mathrm{pH}=7, T=298 \mathrm{~K}$ ). 


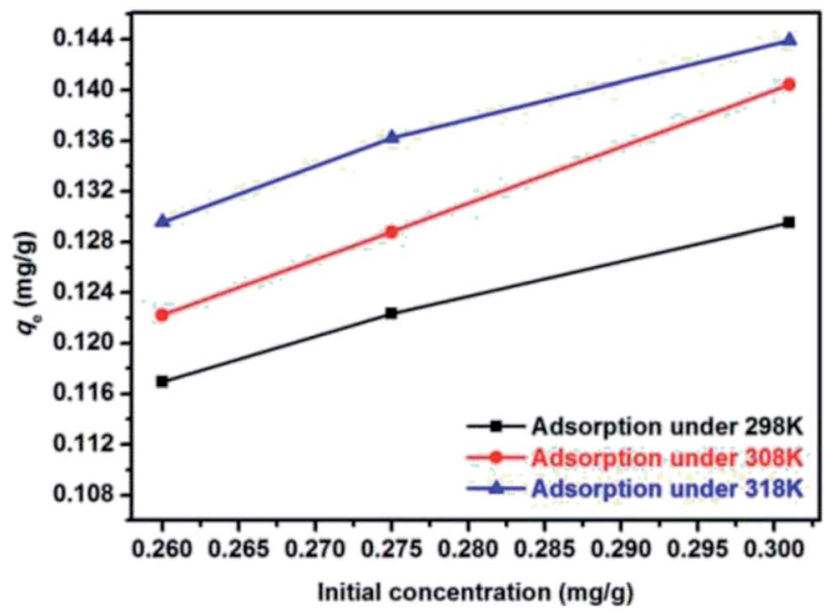

Fig. 8 Effect of temperature on the adsorption process (dosages $=2 \mathrm{~g}$ $\mathrm{L}^{-1}$, solutions $=0.260 \mathrm{mg} \mathrm{L}^{-1} ; 0.275 \mathrm{mg} \mathrm{L}^{-1} ; 0.301 \mathrm{mg} \mathrm{L}^{-1}, \mathrm{~V}=200$ $\mathrm{mL}, \mathrm{pH}=7$, reaction time $=45 \mathrm{~min}$ ).

to the adsorption rate. Moreover, the apparent adsorption rate of SDS-LDH composites was faster than that of inorganic LDH composites. These observations implied that intercalating dodecylsulfate into the interlayer could enhance the hydrophobicity of SDS-LDH composites and intensify the hydrophobic interaction, thereby accelerating the adsorption process compared with that of inorganic LDH composites.

3.2.5 Effect of temperature on the adsorption process of E2. The effect of temperature was presented in Fig. 8 and qe was promoted as the temperature increased. when the temperature was increased from $298 \mathrm{~K}$ to $308 \mathrm{~K}$ and $318 \mathrm{~K}$, the $q_{\mathrm{e}}$ of the SDSLDH composites increased from $0.130 \mathrm{mg} \mathrm{g}^{-1}$ to 0.140 and $0.144 \mathrm{mg}^{-1}$ with the initial E2 concentration was $0.301 \mathrm{mg} \mathrm{L}^{-1}$. This phenomenon suggested that the adsorption processes were endothermic and higher temperatures were favorable to the adsorption process as higher temperatures increased the diffusion rate of the adsorbent (SDS-LDH) and adsorbate (E2) in solution. On the other hand, E2 obtains more energy to overcome the repulsive force with the SDS-LDHs. Therefore, as the temperature increases, the rate of adsorption reaction increases.

\subsection{Adsorption performance of $\mathrm{TP}, \mathrm{PO}_{4}{ }^{3-}$ compounds}

3.3.1 Comparison of the adsorption performances of $\mathrm{PO}_{4}{ }^{3-}$ between SDS-LDH composites and inorganic LDH composites. As shown in Fig. 9, the adsorption process of $\mathrm{PO}_{4}{ }^{3-}$ onto the adsorbents was rapid, especially in the initial $10 \mathrm{~min}$. After which, the process gradually slowed down. The adsorption equilibrium was reached within $120 \mathrm{~min}$. This phenomenon was similar to the preceding experiments and has been explained. Moreover, the removal rates of $\mathrm{PO}_{4}{ }^{3-}$ by the SDSLDH composites reached $85 \%$ when the equilibrium time and dosage were $80 \mathrm{~min}$ and $3 \mathrm{~g} \mathrm{~L}^{-1}$, respectively. Almost the same removal rate was attained by inorganic $\mathrm{LDH}$ at an equilibrium time and dosage of $30 \mathrm{~min}$ and $2 \mathrm{~g} \mathrm{~L}^{-1}$, respectively. These results indicated that the removal capacity of the SDS-LDH

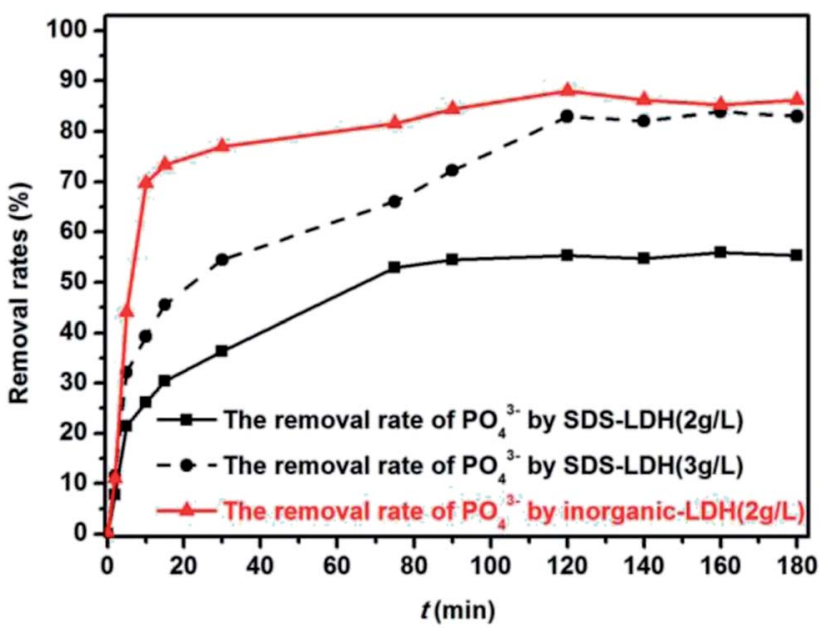

Fig. 9 Effect of contact time for the adsorption of $\mathrm{PO}_{4}{ }^{3-}$ on removal rate (dosages $=2 \mathrm{~g} \mathrm{~L}^{-1}$ for SDS-LDH and inorganic-LDH; $3 \mathrm{~g} \mathrm{~L}^{-1}$ for SDS-LDH, $C_{\text {TP }}=2.952 \mathrm{mg} \mathrm{L}^{-1}, C_{\mathrm{PO}_{4}{ }^{3-}}=2.379 \mathrm{mg} \mathrm{L}^{-1}, \mathrm{~V}=200 \mathrm{~mL}, \mathrm{pH}$ $=7$, reaction time $=180$ minutes, $T=298 \mathrm{~K}$ ).

composites for the adsorbed $\mathrm{PO}_{4}{ }^{3-}$ was slightly reduced after the dodecylsulfate anions intercalated into the interlayer. This phenomenon can be presented in two aspects, namely, contact time and dosage. The data suggested that the hydrophobicity of the adsorbent composites was markedly enhanced after dodecylsulfate anions were intercalated into the interlayer, thereby decreasing the adsorptive capacity to hydrophilic substances, such as $\mathrm{PO}_{4}{ }^{3-}$.

3.3.2 Removal rates of $\mathrm{TP}, \mathrm{PO}_{4}{ }^{3-}$ by SDS-LDH. Fig. 10 shows the changes in the contents of $\mathrm{TP}, \mathrm{PO}_{4}{ }^{3-}$, and organophosphorus. The removal rates of TP and $\mathrm{PO}_{4}{ }^{3-}$ were $65.45 \%$ and $83.01 \%$, respectively, whereas the concentration of organophosphorus remained nearly constant. This phenomenon indicated that the SDS-LDH composites mainly removed $\mathrm{PO}_{4}{ }^{3-}$ to reduce the contents of TP.

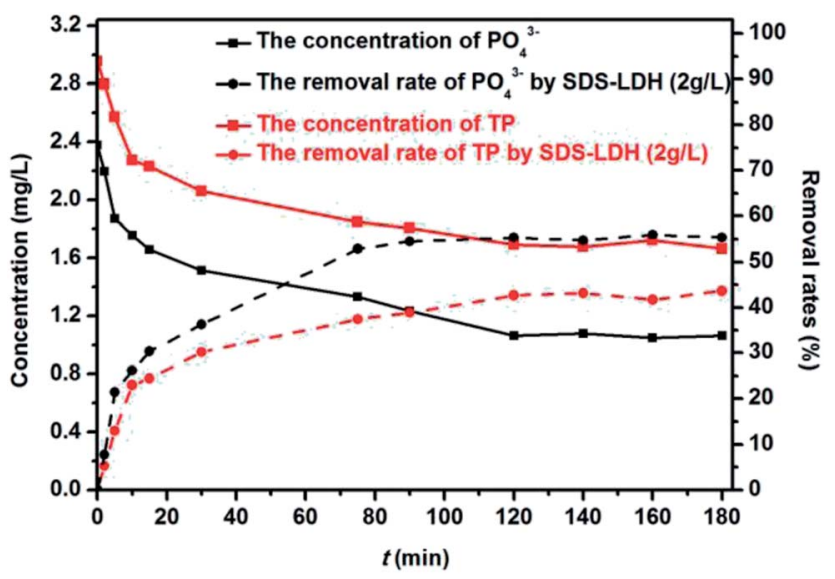

Fig. 10 Removal rates of TP, $\mathrm{PO}_{4}{ }^{3-}$ by SDS-LDH composites $\left(C_{\mathrm{SDS}-}\right.$ $\mathrm{LDH}=2 \mathrm{~g} \mathrm{~L}^{-1}, C_{\mathrm{TP}}=2.952 \mathrm{mg} \mathrm{L}^{-1}, \mathrm{C}_{\mathrm{PO}_{4}{ }^{3-}}=2.379 \mathrm{mg} \mathrm{L}^{-1}, \mathrm{~V}=200 \mathrm{~mL}$, $\mathrm{pH}=7$, reaction time $=180 \mathrm{~min}, T=298 \mathrm{~K}$ ). 


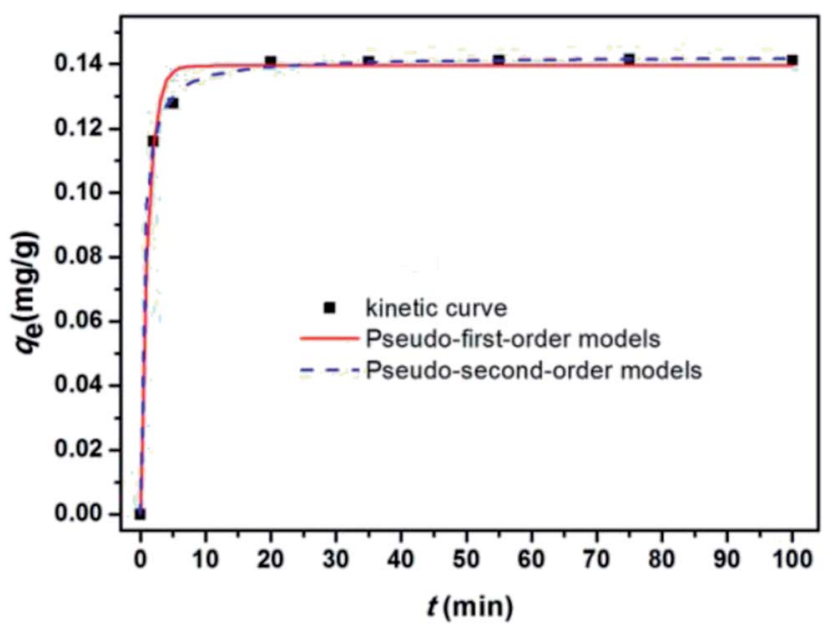

Fig. 11 Nonlinear fitting of the pseudo-first-order and pseudosecond-order models for the adsorption of E2 onto SDS-LDH composites.

\subsection{Adsorption theory discussion}

3.4.1 Adsorption kinetics. Adsorption kinetics reflects the adsorbent efficiency and application potential of modified materials. Adsorption kinetics is generally used to describe the dynamic behavior and explore the adsorption mechanism. To investigate the uptake kinetics of E2 onto SDS-LDH and to examine the mechanism and rate-controlling steps in the overall adsorption process, pseudo-first order and pseudosecond order kinetics models was adopted to fit the experimental data.

Fig. 11 show the kinetic curves of E2, corresponding results of the fitting models. Parameters $q_{\mathrm{e}}, k$, and the correlation coefficient $\left(R^{2}\right)$ are listed in Table 5 . As shown in Table 5 , the pseudo-second-order model exhibited a higher correlation coefficient $\left(R^{2}\right)$ for $\mathrm{E} 2$, and the equilibrium adsorption amounts $\left(q_{\mathrm{e} 2(\mathrm{cal})}\right)$ calculated by the pseudo-second-order model were approximately identical to the experimental data $\left(q_{\mathrm{e}(\exp )}\right)$. These results implied that the adsorptive reaction of E2 onto SDS-LDH composites could be appropriately described by the pseudosecond-order model and that the adsorption rate was proportional to the square of the number of free sites.

3.4.2 Adsorption isotherm. Adsorption isotherms are typically used to describe the adsorption characteristics, including adsorption capacity, adsorption strength, and adsorption state. Adsorption capacity is an important factor for evaluating SDSLDH composites. Two common models are the Langmuir model and Freundlich model. The Langmuir model is based on the ideal assumption: it supposes that the adsorbent surface is

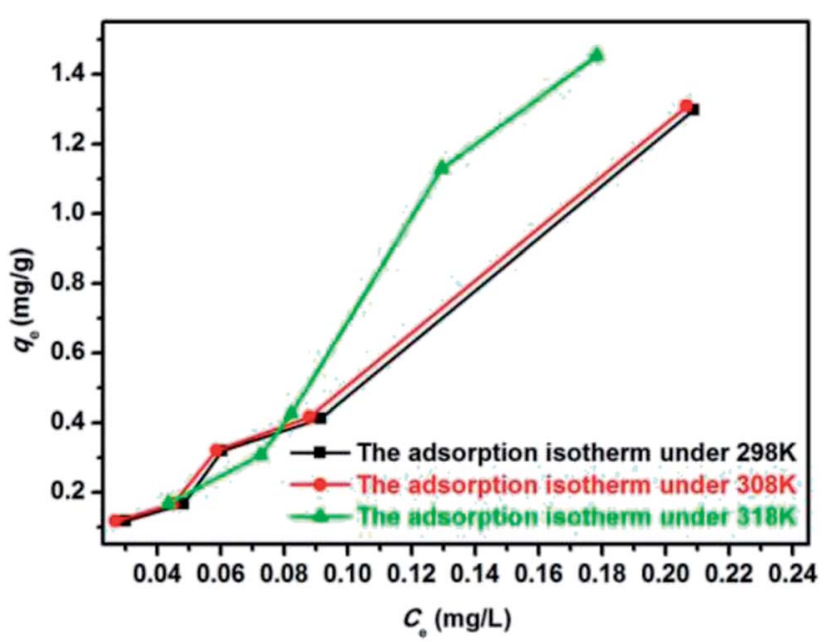

Fig. 12 Adsorption isotherm for the adsorption of E2 onto SDS-LDH composites.

completely homogeneous with identical adsorption sites and that the adsorption is a monolayer coverage according to the assumption. The Freundlich model is an empirical equation that assumes a heterogeneous adsorptive energy and is not restricted to the formation of a monolayer on the adsorbent surface.

Fig. 12 and 13 show the adsorption isotherm curves of E2 under different temperatures and the corresponding linear fitting of the Langmuir and Freundlich (inset) models. Parameters $Q_{\mathrm{m}}, K_{\mathrm{L}}, n, K_{\mathrm{f}}$, and $R^{2}$ are listed in Table 6 .

As shown in Table 6, the Freundlich model exhibited a higher $R^{2}$ for the adsorption process, indicating that the Freundlich equation provided a better fit for the experimental data than the Langmuir equation. The Langmuir isotherm is typically applicable to a homogeneous uptake surface where all of the uptake sites have an equal adsorbate affinity, whereas the Freundlich isotherm model assumes the heterogeneity of the uptake surfaces expressed by the Freundlich equation. Adsorption type is not restricted to the formation of a monolayer, and the adsorption sites are energetically unequal. Moreover, the higher $K_{\mathrm{f}}$ values indicated that E2 had a high affinity for SDS-LDH composites. This phenomenon implied that the surface nature of the SDS-LDH composites transformed from hydrophilic to hydrophobic after dodecylsulfate anions were intercalated into the interlayer and replaced the interior $\mathrm{NO}_{3}{ }^{-}$and $\mathrm{CO}_{3}{ }^{2-}$, thereby increasing its affinity for hydrophobic compounds, such as E2, through adsolubilization mechanisms.

Basing on the initial slope of the isothermal adsorption curve, B. Wang et al. ${ }^{\mathbf{1 6}}$ divided the liquid single component

Table 5 Parameters fitted by the pseudo-first-order and pseudo-second-order models

\begin{tabular}{|c|c|c|c|c|c|c|c|c|}
\hline Material & Pollutant & $q_{\mathrm{e}(\exp )}\left(\mathrm{mg} \mathrm{g}^{-1}\right)$ & $k_{1}\left(\mathrm{~s}^{-1}\right)$ & $q_{\mathrm{e} 1(\mathrm{cal})}\left(\mathrm{mg} \mathrm{g}^{-1}\right)$ & $R^{2}$ & $k_{2}\left(\mathrm{~g} \mathrm{mg}^{-1} \mathrm{~s}^{-1}\right)$ & $q_{\mathrm{e} 2(\mathrm{cal})}\left(\mathrm{mg} \mathrm{g}^{-1}\right)$ & $R^{2}$ \\
\hline & $\mathrm{TP}$ & 0.644 & 0.06 & 0.605 & 0.97 & 0.12 & 0.673 & 0.99 \\
\hline
\end{tabular}




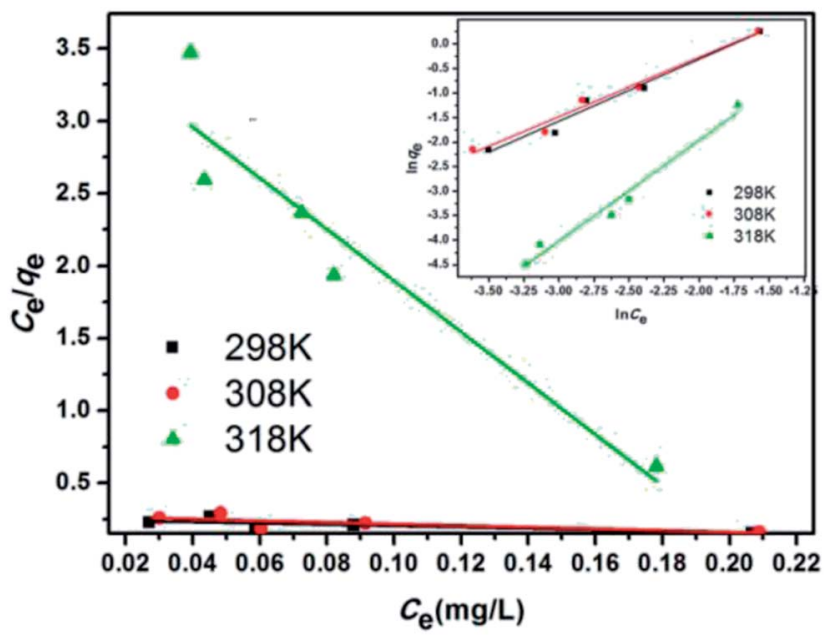

Fig. 13 Linear fitting of the Langmuir and Freundlich (inset) models for the adsorption of E2 onto SDS-LDH composites.

adsorption isotherm into four types, namely, types $\mathrm{S}, \mathrm{L}, \mathrm{H}$, and $\mathrm{C}$, and each type was divided into five groups. The adsorption isotherm curves obtained under different temperatures in this experiment were close to type $\mathrm{C}$, which is a common adsorption isotherm curve for very hydrophobic organic compounds. This finding demonstrated that the competitive adsorption between the solvent and the adsorbate onto the binding sites of the adsorbents was minimal and that the adsorbate had a certain proportion of distribution in the solvent and the adsorbent, reflecting a constant distribution mechanism.

3.4.3 Adsorption thermodynamics. Adsorption thermodynamics is generally used to determine whether an adsorptive reaction can occur spontaneously in the real process by evaluating the Gibbs free energy change, which is considered a basic standard for assessing spontaneity. Adsorption thermodynamics can also be applied to assess the effect of temperature by evaluating the heat change of the adsorption reactions.

The thermodynamic parameters of $\Delta H, \Delta S, \Delta G$, and $R^{2}$ are listed in Table 7. As shown, the adsorption processes were endothermic, and higher temperatures were conducive to the adsorptive reaction, as $\Delta H$ of the SDS-LDH composites was $47.39 \mathrm{KJ} \mathrm{mol}^{-1}$. The $\Delta S$ of the SDS-LDH composites was $173.80 \mathrm{~J}$ $\mathrm{mol}^{-1} \mathrm{~K}^{-1} . \Delta G$ at 298,308 , and $318 \mathrm{~K}$ were calculated as -4.33 , -6.48 , and $-7.81 \mathrm{~kJ} \mathrm{~mol}^{-1}$, respectively. These data confirmed that the adsorbent particles had a good affinity toward E2 and that the adsorption process occurred spontaneously under natural conditions.

\subsubsection{Adsorption mechanism}

3.4.4.1 Hydrophobicity of SDS-LDH. As shown in Scheme 3, the dodecylsulfate anions were assembled into the LDH interlayers through electrostatic attraction and hydrogen bonding interaction. According to the XRD characterization of the SDSLDH composites, the dodecylsulfate anions existed in a single-layer vertical pattern among the lamella. The hydrophobic properties of SDS-LDH composites can be explained from two aspects. One is ion polarization, the ionic radius of $-\mathrm{OSO}_{3}$ - is large and $-\mathrm{OSO}_{3}$ - has poor binding force for the outer electrons, which make the outer electrons prone to deformity. On the contrast, the ionic radii of $\mathrm{Mg}^{2+}$ and $\mathrm{Al}^{3+}$ were relatively small and occupied with high positive charges. Consequently, these metallic cation could induced relative displacement between the outer electrons of $-\mathrm{OSO}_{3}$ - and nucleus, and then ion polarization occurred which means the covalent component of SDS-LDH composites was increased compared with that of the inorganic LDH composites, and the solubility in water would inevitably decrease. Another reason is the function of hydrophobic dodecylsulfate anions, the alkyl chains (from dodecylsulfate anions) occupied the interlayer regions and formed a compact and ordered structure, ${ }^{32}$ resulting in the formation of some hydrophobic phase existing in the interlayer region.

3.4.4.2 Mechanism of the adsorption process of E2. As shown in Scheme 4, both hydrogen bond interaction and hydrophobic interaction between $\mathrm{E} 2$ and SDS-LDH composites were the main force during the process of adsorption. When the $\mathrm{pH}$ values of aqueous solution was less than 9.0, the electrostatic repulsion would not be the major force affecting the adsorption process due to that $\mathrm{E} 2\left(\mathrm{p} K_{\mathrm{a}}=10.71\right)$ was mainly existed in molecule

Table 6 Parameters fitted by the Langmuir and Freundlich models

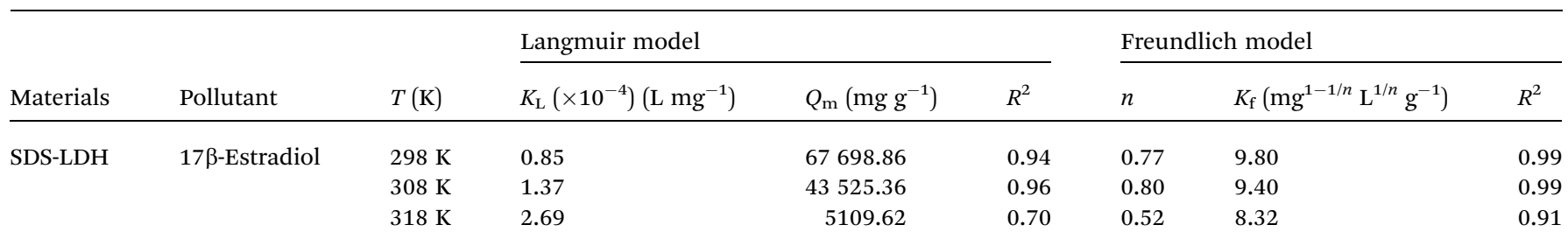

Table 7 Thermodynamic parameters for the adsorption processes

\begin{tabular}{llllll}
\hline Material & $C_{0}\left(\mathrm{mg} \mathrm{L}^{-1}\right)$ & $T(\mathrm{~K})$ & $\Delta S\left(\mathrm{~J} \mathrm{~mol}^{-1} \mathrm{~K}^{-1}\right)$ & $\Delta H\left(\mathrm{~kJ} \mathrm{~mol}^{-1}\right)$ & $\Delta G\left(\mathrm{~kJ} \mathrm{~mol}{ }^{-1}\right)$ \\
\hline \multirow{2}{*}{ SDS-LDH } & 0.30143 & 298 & & -4.33 \\
& & 308 & 173.80 & 47.39 & -6.48 \\
& 318 & & -7.81
\end{tabular}



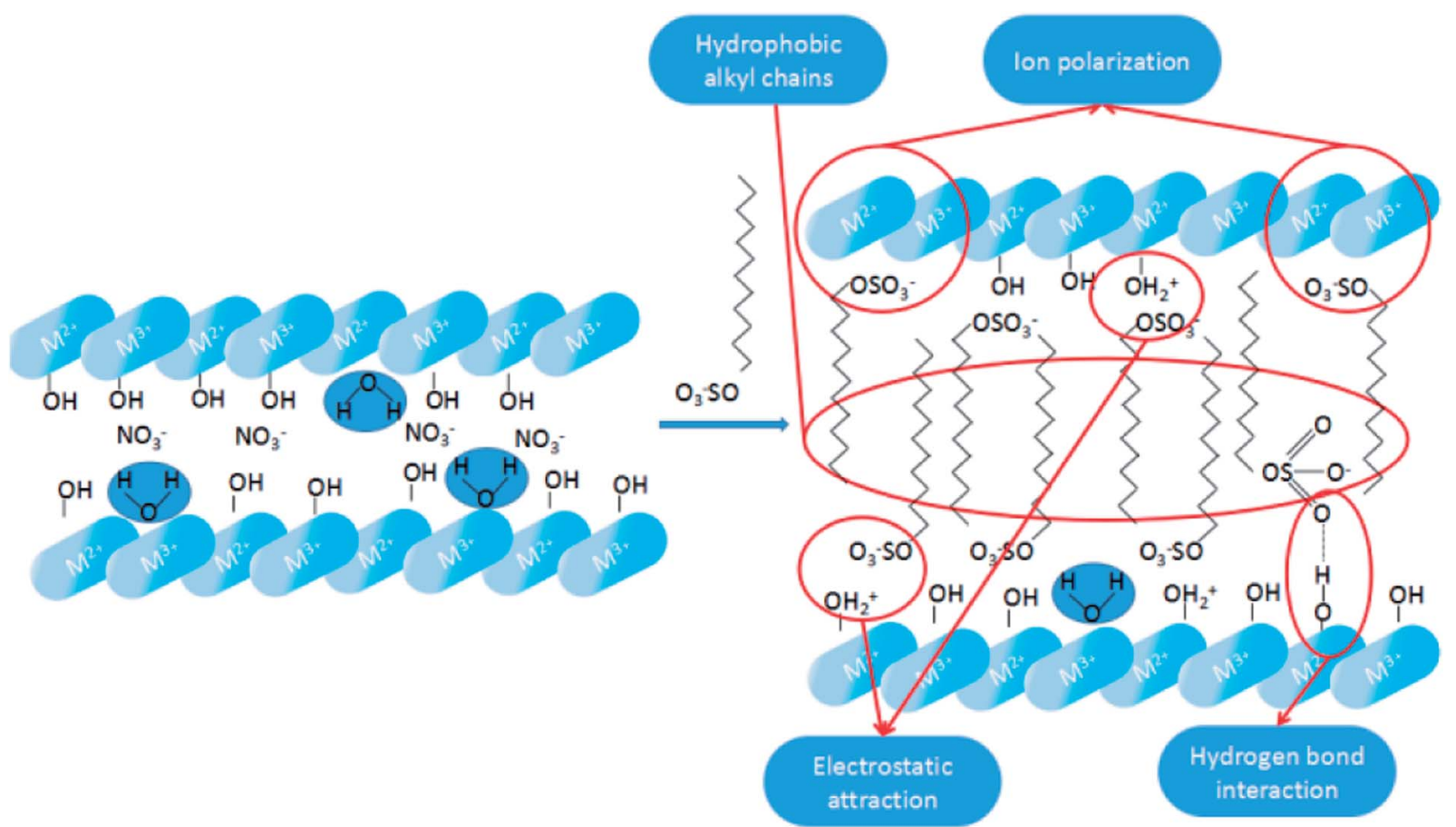

Scheme 3 Illustration for the hydrophobic of SDS-LDH composites.

state within this $\mathrm{PH}$ range. Under this situation, the interaction between hydroxyl (from E2) and sulfonic group (from intercalated dodecylsulfate anions) can formed hydrogen bond which was regarded as one of the major force during the adsorption process. ${ }^{33}$ Based on the explanation for hydrophobic of SDSLDH composites in Chapter 3.4.4.1, another important force during the process of adsorption was adsolubilization. ${ }^{34,35}$ Namely, the aggressive of the dodecylsulfate anions especially some hydrophobic alkyl chains in the SDS-LDH composites interlayers would result in some hydrophobic phase and that hydrophobic phase was expected to have the ability to solubilize hydrophobic organic compounds..$^{32,34,35}$ When the $\mathrm{pH}$ values was exceeded 9.0, E2 was mainly in the form of anion, under this situation, the intense electrostatic repulsion keep the ionic state-E2 away from the SDS-LDH composites and adsorption efficiency was inevitable decreased.

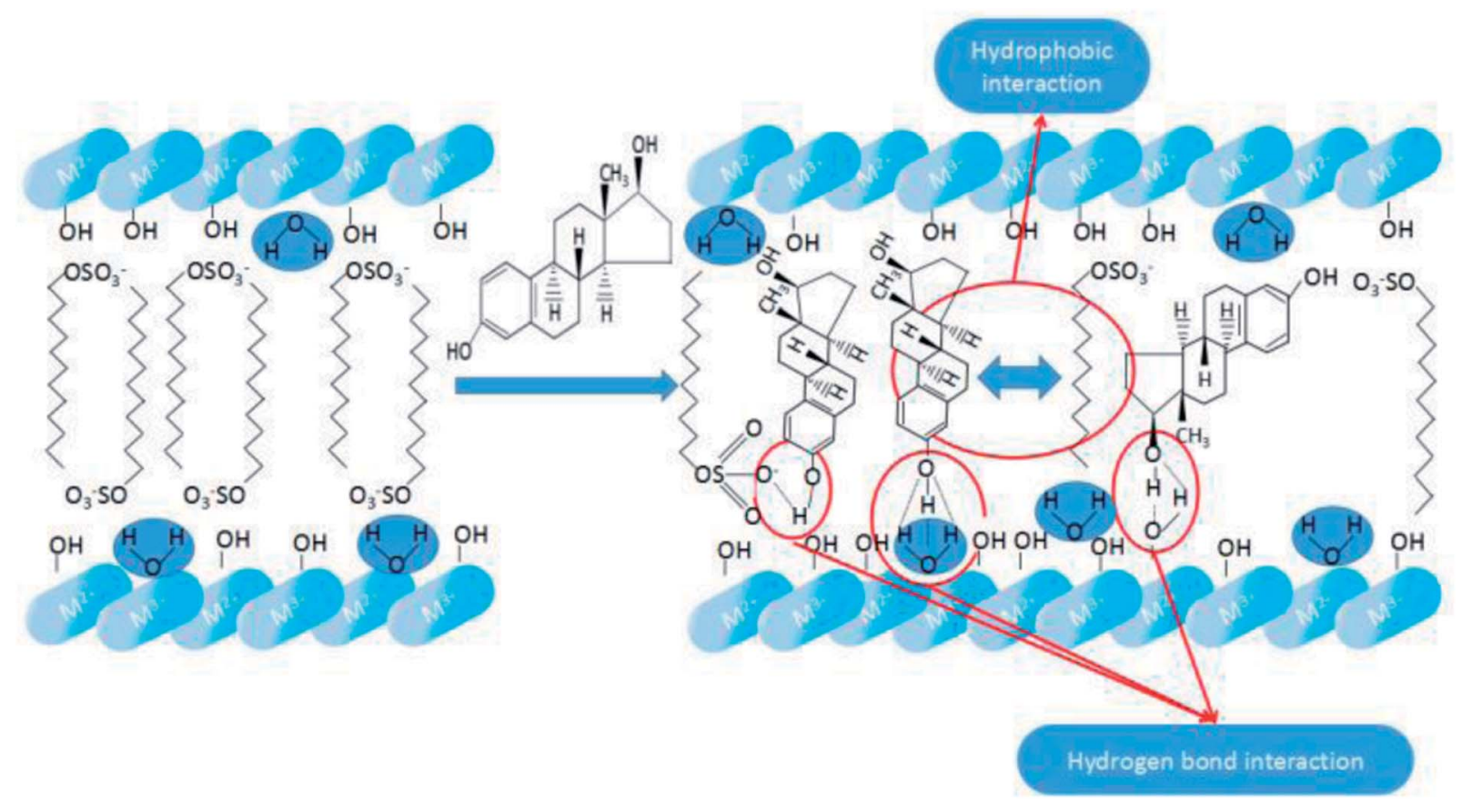

Scheme 4 Mechanistic illustration for the adsorption of E2 onto SDS-LDH composites. 


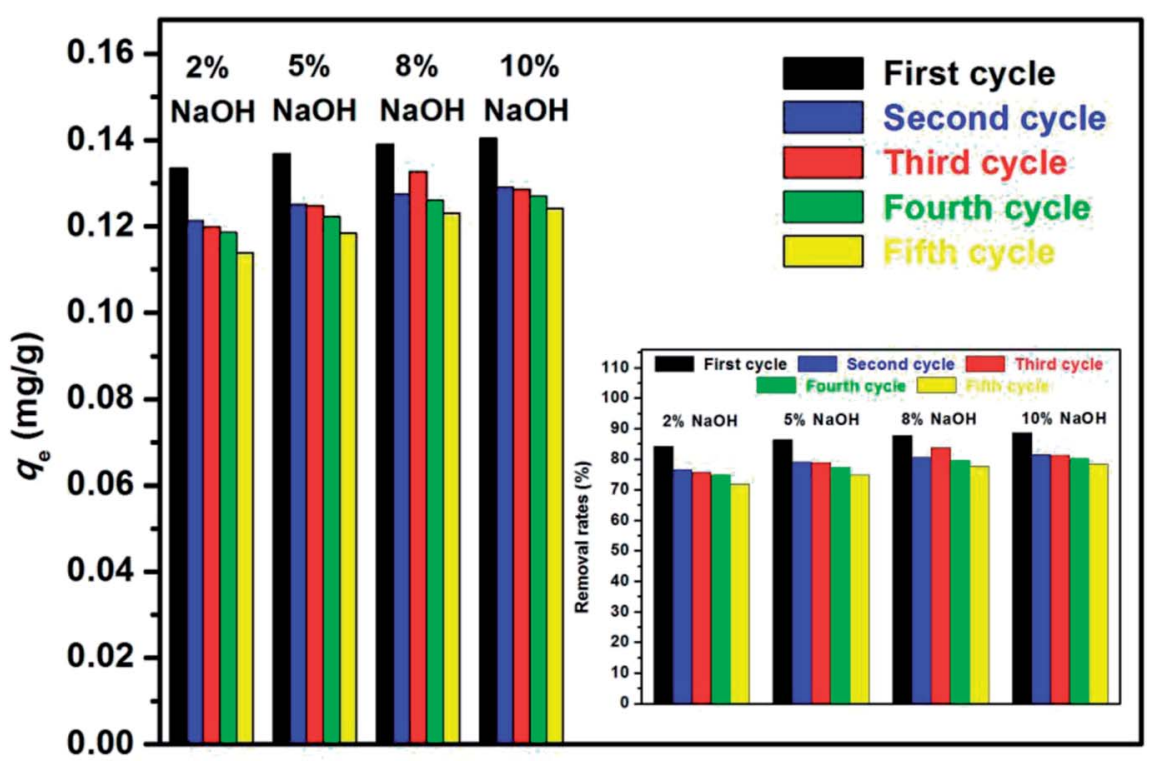

Fig. 14 Effect of recycling time for the adsorption of E2 on the equilibrium adsorption amount $q_{\mathrm{e}}$ and the removal rate (inset).

\subsection{Recycle and reuse of SDS-LDH composites}

The regeneration performance of adsorbents is a critical factor in evaluating the practicability of adsorbents and improving the process economics. The experimental results for solution $\mathrm{pH}$, where the adsorption process of $\mathrm{E} 2$ onto the adsorbents was restrained at high alkali conditions, suggested that the adsorbed SDS-LDH composites were highly likely to be regenerated by alkali treatment.

Adsorption-desorption cycles were repeated five times. To compare the efficiency of the treatment under different concentrations of $\mathrm{NaOH}$, the cyclic adsorption experiments were divided into four groups, which were occupied with $2 \%$, $5 \%, 8 \%, 10 \% \mathrm{NaOH}$, respectively, and marked as groups A, B, C, and $\mathrm{D}$. The adsorbed materials of each group were treated with the corresponding concentrations of $\mathrm{NaOH}$ alkali solution. The results are shown in Fig. 14.

Alkaline treatment achieved a good regeneration performance of the adsorbents. The $q_{\mathrm{e}}$ values of the initial adsorption of groups A, B, C, and D were $0.133,0.137,0.139$, and $0.140 \mathrm{mg}$ $\mathrm{g}^{-1}$, respectively, and their corresponding removal rates were $84.19 \%, 86.34 \%, 87.71 \%$, and $88.60 \%$. After five times of recycle, the $q_{\mathrm{e}}$ values were measured as $0.114,0.118,0.123$, and $0.124 \mathrm{mg} \mathrm{g}^{-1}$, respectively, and their corresponding removal rates were $71.84 \%, 74.72 \%, 77.63 \%$, and $78.28 \%$. The results revealed that the regenerated adsorbents showed an excellent reusability and stability with only a slight decrease in $q_{\mathrm{e}}$. Moreover, group D exhibited the best regeneration performance among these groups, indicating that the efficiency of the treatment was improved as the $\mathrm{NaOH}$ concentration was increased within the limits.

\section{Conclusion}

SDS-LDH composites were successfully synthesized by intercalating dodecylsulfate anions into the interlayer of LDH. The formed material exhibited a spreading lamellar structure, and its layers were thin and diffused irregularly, which were conducive for a superb adsorption performance toward tracelevel E2. The maximum adsorption equilibrium amount and the adsorption equilibrium time at $298 \mathrm{~K}$ were $0.142 \mathrm{mg} \mathrm{g}^{-1}$ and $20 \mathrm{~min}$, respectively. The suitable $\mathrm{pH}$ and adsorbent dosage conditions for absorbing E2 were 7 and $2 \mathrm{~g} \mathrm{~L}^{-1}$, respectively. The presence of various ions in aqueous solution $\left(\mathrm{Na}^{+}, \mathrm{SO}_{4}{ }^{2-}, \mathrm{CI}^{-}\right.$, and $\left.\mathrm{H}_{2} \mathrm{PO}_{4}{ }^{-}\right)$did not adversely affect the adsorption process. The pseudo-second-order model was better fitted with the kinetic data than the pseudo-first-order model, and the Freundlich isotherm was better correlated than the Langmuir isotherm. The adsorption processes were spontaneous and endothermic, and an excellent recycle was obtained in the cyclic adsorption experiments. Moreover, the removal capacity of SDS-LDH composites for inorganic ion $\left(\mathrm{PO}_{4}{ }^{3-}\right)$ was reduced and presented in two aspects (contact time and dosage) compared with that of the inorganic LDH composites.

Therefore, we believe that SDS-LDH is a technically feasible, easily synthesizable, highly efficient, stably functional, and cost-effective adsorbent and it could be applied in the treatment of secondary effluent of wastewater treatment plants contaminated by trace-level E2 compounds.

\section{Conflicts of interest}

There are no conflicts to declare.

\section{Acknowledgements}

The authors wish to acknowledge the financial support from the 2017 Chongqing University "Graduate Student Research Innovation Project" (CYS17006) and the National Natural Scientific Foundation of China (51778082). 


\section{References}

1 L. Fernandez, W. Borzecka, Z. Lin, R. J. Schneider, K. Huvaere, V. I. Esteves, A. Cunha and J. P. C. Tome, Nanomagnet-photosensitizer hybrid materials for the degradation of E2 in batch and flow modes, Dyes Pigm., 2017, 142, 535-543.

2 F. A. Caliman and M. Gavrilescu, Pharmaceuticals, personal care products and endocrine disrupting agents in the environment: a review, Clean, 2009, 37, 277-303.

3 R. G. Ziegler, et al., Epidemiologic studies of estrogen metabolism and breast cancer, Steroids, 2015, 99(Pt A), 6775.

4 T. T. Schug, A. Janesick, B. Blumberg and J. J. Heindel, Endocrine disrupting chemicals and disease susceptibility, J. Steroid Biochem. Mol. Biol., 2011, 127, 204-215.

5 Q. Wang, et al., Polypropylene/layered double hydroxide nanocomposites, J. Mater. Chem., 2012, 22(36), 19113-19121.

6 M. Nasu, Study on endocrine disrupting chemicals in wastewater treatment plants, Water Sci. Technol., 2001, 43, 101-108.

7 C. P. Silva, D. L. Lima, M. Otero and V. I. Esteves, Photosensitized Degradation of $17 \beta$-estradiol and $17 \alpha-$ ethinylestradiol: Role of Humic Substances Fractions, $J$. Environ. Qual., 2016, 45, 693-700.

8 H. M. Coleman, B. R. Eggins and J. A. Byrne, Photocatalytic degradation of E2 on immobilised $\mathrm{TiO}_{2}$, Appl. Catal., B, 2000, 24, 311-315.

9 S. Irmak, O. Erbatur and A. Aydin, Degradation of E2 and bisphenol $\mathrm{A}$ in aqueous medium by using ozone and ozone/UV tech-niques, J. Hazard. Mater., 2005, 126, 54-62.

10 T. Fukuhara, S. Iwasaki and M. Kawashima, Adsorbability of estrone and E2 in water onto activated carbon, Water Res., 2006, 40, 241-248.

11 Y. Yoon, P. Westerhoff and S. A. Snyder, Adsorption of ${ }^{3} \mathrm{H}-$ labeled E2 on powdered activated carbon, Water, Air, Soil Pollut., 2005, 166, 343-351.

12 L. Yang, et al., Sexually disrupting effects of nonylphenol and diethylstilbestrol on male silver carp (Carassius auratus) in aquatic microcosms, Ecotoxicol. Environ. Saf., 2008, 71(2), 400.

13 Q. Wang, et al., Polypropylene/layered double hydroxide nanocomposites, J. Mater. Chem., 2012, 22(36), 19113-19121.

$14 \mathrm{~J}$. Wang, et al., The Influence of the Charge Compensating Anions of Layered Double Hydroxides (LDHs) in LDH-NS/ Graphene Oxide Nanohybrid for $\mathrm{CO}_{2}$ Capture, J. Nanosci. Nanotechnol., 2018, 18(4), 2956-2964.

$15 \mathrm{Z}$. P. Xu, et al., Surface charging of layered double hydroxides during dynamic interactions of anions at the interfaces, $J$. Colloid Interface Sci., 2008, 326(2), 522-529.

16 B. Wang, et al., Surface modification of layered double hydroxides and incorporation of hydrophobic organic compounds, Mater. Chem. Phys., 2005, 92(1), 190-196.

17 F. Bruna, R. Celis, M. Real and J. Cornejo, Organo/LDH nanocomposite as an adsorbent of polycyclic aromatic hydrocarbons in water and soil-water systems, J. Hazard. Mater., 2012, 225, 74-80.

18 R. R. Shan, et al., Adsorption of Cd(II) by Mg-Al-CO 3 - and magnetic Fe $3 \mathrm{O}$ 4/Mg-Al-CO 3 -layered double hydroxides: Kinetic, isothermal, thermodynamic and mechanistic studies, J. Hazard. Mater., 2015, 299(9), 42-49.

19 M. T. Rahman, et al., A novel method to delaminate nitrateintercalated $\mathrm{Mg}$ Al layered double hydroxides in water and application in heavy metals removal from waste water, Chemosphere, 2018, 203, 281-290.

20 M. Dinari and R. Tabatabaeian, Ultra-fast and highly efficient removal of cadmium ions by magnetic layered double hydroxide/guargum bionanocomposites, Carbohydr. Polym., 2018, $192,317$.

21 S. Combalbert and G. Hernandez-Raquet, Occurrence, fate and biodegradation of estrogens in sewage and manure, Appl. Microbiol. Biotechnol., 2010, 86, 1671-1692.

22 Y. You, H. Zhao and G. F. Vance, Surfactant-enhanced adsorption of organic compounds by layered double hydroxides, Colloids Surf., A, 2002, 205, 161-172.

23 R. Rojas, F. Bruna, C. P. de Pauli, M. A. Ulibarri and C. E. Giacomelli, The effect of interlayer anion on the reactivity of $\mathrm{Mg}-\mathrm{Al}$ layered double hydroxides: improving and extending the customization capacity of anionic clays, J. Colloid Interface Sci., 2011, 359, 136-141.

24 R. Scotti, et al., Azul de metileno imobilizado na celulose/ $\mathrm{TiO}_{2}$ e $\mathrm{SiO}_{2} / \mathrm{TiO}_{2}$ : propriedades eletroquímicas e planejamento fatorial Methylene blue immobilized in cellulose $/ \mathrm{TiO}_{2}$ and $\mathrm{SiO}_{2} / \mathrm{TiO}_{2}$ : electrochemical properties and factorial design, Quim. Nova, 2006, 29(2), 208-212.

25 C. H. Giles, T. H. MacEwan, S. N. Nakhwa and D. Smith, Studies in adsorption. PartXI. A system of classification of solution adsorption isotherms, and its use in diagnosis of adsorption mechanisms and in measurement of specific surface areas of solids, J. Chem. Soc., 1960, 3973-3993.

26 P. Zhang, et al., Effective intercalation of sodium dodecylsulfate (SDS) into hydrocalumite: Mechanism discussion via near-infrared and mid-infrared investigations, Spectrochim. Acta, Part A, 2015, 149, 166-172.

27 M. Serdechnova, et al., Interlayer intercalation and arrangement of 2-mercaptobenzothiazolate and 1,2,3benzotriazolate anions in layered double hydroxides: In situ X-ray diffraction study, J. Solid State Chem., 2016, 233, 158-165.

28 S. I. Omonmhenle and I. J. Shannon, Synthesis and characterisation of surfactant enhanced $\mathrm{Mg}-\mathrm{Al}$ hydrotalcite-like compounds as potential 2-chlorophenol scavengers, Appl. Clay Sci., 2016, 127-128, 88-94.

29 R. R. Shan, et al., Adsorption of Cd(II) by Mg-Al-CO 3 - and magnetic Fe $3 \mathrm{O}$ 4/Mg-Al-CO 3 -layered double hydroxides: Kinetic, isothermal, thermodynamic and mechanistic studies, J. Hazard. Mater., 2015, 299(9), 42-49.

30 L. G. Yan, et al., Adsorption of phosphate from aqueous solution by hydroxy-aluminum, hydroxy-iron and hydroxyiron-aluminum pillared bentonites, J. Hazard. Mater., 2010, 179(1-3), 244. 
31 Y. Xue, H. Hou and S. Zhu, Characteristics and mechanisms of phosphate adsorption onto basic oxygen furnace slag, $J$. Hazard. Mater., 2009, 162(2), 973-980.

32 Q. Zhao, Z. Chang, X. Lei and X. Sun, Adsorption Behavior of Thiophene from Aqueous Solution on Carbonate- and Dodecylsulfate-Intercalated $\mathrm{ZnAl}$ Layered Double Hydroxides, Ind. Eng. Chem. Res., 2011, 50, 10253-10258.
33 P. C. Pavan, E. Luis Crepaldi and J. B. Valim, Sorption of Anionic Surfactants on Layered Double Hydroxides, $J$. Colloid Interface Sci., 2000, 229, 346-352.

34 J. Y. Wu, J. H. Harwell and E. A. O'Rear, Two-dimensional Reaction Solvents: Surfactant Bilayers in the Formation of Ultrathin Films, Langmuir, 1987, 3(4), 531-537.

35 K. Esumi and S. Yamamoto, Adsorption of sodium dodecyl sulfate on hydrotalcite and adsolubilization of 2-naphthol, Colloids Surf., A, 1998, 137(1-3), 385-388. 